Article

\title{
Heterocycle Effects on the Liquid Crystallinity of Terthiophene Analogues
}

\author{
David F. Ester®, Declan McKearney® ${ }^{\circledR}$, Khrystyna Herasymchuk and Vance E. Williams * \\ Department of Chemistry, Simon Fraser University, 8888 University Drive, Burnaby, BC V5A 1S6, Canada \\ * Correspondence: vancew@sfu.ca
}

Received: 18 June 2019; Accepted: 13 July 2019; Published: 19 July 2019

\begin{abstract}
Liquid crystalline self-assembly offers the potential to create highly ordered, uniformly aligned, and defect-free thin-film organic semiconductors. Analogues of one of the more promising classes of liquid crystal semiconductors, 5,5"-dialkyl- $\alpha$-terthiophenes, were prepared in order to investigate the effects of replacing the central thiophene with either an oxadiazole or a thiadiazole ring. The phase behaviour was examined by differential scanning calorimetry, polarized optical microscopy, and variable temperature $\mathrm{x}$-ray diffraction. While the oxadiazole derivative was not liquid crystalline, thiadiazole derivatives formed smectic $\mathrm{C}$ and soft crystal lamellar phases, and maintained lamellar order down to room temperature. Variation of the terminal alkyl chains also influenced the observed phase sequence. Single crystal structures revealed the face-to-face orientation of molecules within the layers in the solid-state, a packing motif that is rationalized based on the shape and dipole of the thiadiazole ring, as corroborated by density functional theory (DFT) calculations. The solution opto-electronic properties of the systems were characterized by absorption and emission spectroscopy, cyclic voltammetry, and time-dependent density functional theory (TD-DFT).
\end{abstract}

Keywords: organic semiconductors; self-assembly; lamellar structures; 2D charge transport pathways (or 2D lamellar arrays); structure-property relationships; liquid crystals

\section{Introduction}

Organic semiconductors are attractive materials due to their light weight, mechanical flexibility, tunability through chemical modification, and compatibility with solution processing techniques that allow for low-cost device fabrication [1-4]. Although they have proven suitable for applications such as light emitting diodes (OLEDs) [5-8], field-effect transistors (OFETs) [9-13], and photovoltaics (OPVs) [14-17], an organic semiconductor's performance is ultimately limited by its supramolecular ordering. Structural defects, poor alignment, and grain boundaries all degrade mobility [18-21]. Despite significant efforts to address these issues through chemical modification and sample processing [22-30] reliable approaches for optimizing supramolecular ordering for high performance organic semiconductors based on 3D crystalline materials remain elusive.

Liquid crystals (LCs) represent a promising alternative to common crystalline solid organic semiconductors, owing to their ability to self-assemble into ordered self-healing structures capable of uniform alignment over large areas, and with supramolecular order that can be maintained in the solid-state [31-37]. Although columnar phases have been the most commonly explored liquid crystalline semiconductors, their one dimensional charge conduction is highly susceptible to defects [38-44]. More recently, smectic LCs have emerged as more attractive candidate materials since their layered structure permits conduction in two dimensions, potentially leading to more consistent performance [45-49]. Simultaneously tuning both the opto-electronic properties and self-assembly of smectic LC materials represents an ongoing challenge in their exploitation as organic semiconductors. 
Terthiophene derivatives are among the most extensively studied smectic LC organic semiconductors. Of particular interest, the 5,5" $-\operatorname{di}\left(n\right.$-alkyl)terthiophenes, $\mathbf{T h}_{\mathbf{3}}(n)(n=7-10)$ (Figure 1), exhibit both crystalline lamellar phases at room temperature and smectic $\mathrm{F}(\mathrm{SmF})$ and $\mathrm{C}(\mathrm{SmC})$ phases at elevated temperatures [50-55]. Whereas charge carrier mobility increases in highly ordered lamellar crystalline phases $[46,56,57]$ overlying smectic LC phases enable uniformly aligned, defect-free thin-films to be formed during processing [58]. For example, Hanna demonstrated that films of $\mathbf{T h}_{\mathbf{3}} \mathbf{( 8 )}$ obtained from liquid crystalline phases at elevated temperatures exhibit improved OFET mobilities in the room temperature crystalline state $[59,60]$. In addition, samples cooled through multiple similar LCs, such as SmC and SmF phases, tend to possess improved morphologies $[37,61]$.

The majority of studies on terthiophene-based mesogens have focused on modification of the terminal groups $[37,50-52,62-66]$, whereas changes to the central terthiophene core have largely been neglected [57]. In the present work, we replaced the central thiophene of $\mathbf{T h}_{3}(n)$ with either oxadiazole or thiadiazole rings to afford Th-Oxd-Th(n) and Th-Thd-Th(n), respectively (Figure 1), and examined the impact of these changes on both the phase behavior and photophysical properties. While these rings are more electron-accepting than thiophene, allowing for the tuning of opto-electronic properties, their geometric similarities to thiophene and the precedent of oxadiazole- and thiadiazole-based mesogens in the literature [67-71] suggested that these compounds would be compatible with the formation of smectic phases similar to those of $\mathrm{Th}_{3}(n)$.

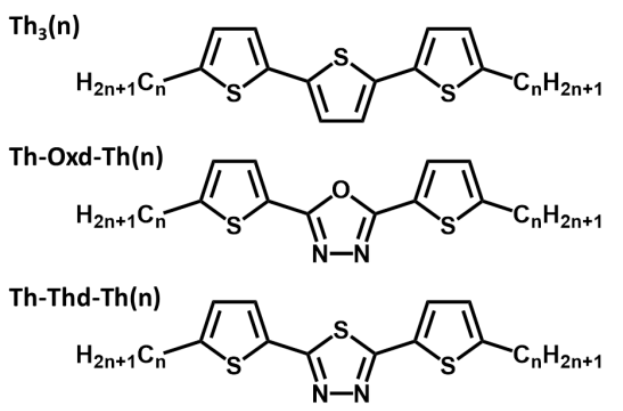

Figure 1. The structures of compounds Th3(n), Th-Oxd(n) and Th-Thd-Th(n).

Our initial efforts focused on a comparison of the opto-electronic properties and self-assembly of Th-Oxd-Th(10) and Th-Thd-Th(10) to those of $\mathrm{Th}_{3}(\mathbf{1 0})$. Based on the promising liquid crystalline properties of Th-Thd-Th(10), we extended our study to Th-Thd-Th $(n)$ for $(n=4,6,8,12)$ to more fully examine this series. To our knowledge, this represents the first systematic examination of either of these systems [72].

\section{Results and Discussion}

\subsection{Synthesis}

Our initial studies focused on the $n=10$ derivatives because the parent terthiophene system $\mathbf{T h}_{\mathbf{3}}(\mathbf{1 0})$ was reported to form stable SmC and SmF LC phases [50]. $\mathbf{T h}_{\mathbf{3}}(\mathbf{1 0 )}$ was prepared in order to confirm the literature reports and to facilitate direct comparison to the newly synthesized thiadiazole and oxadiazole analogues. Terthiophene was obtained by Kumada coupling of 2,5-dibromothiophene and 2-bromothiophene [73]. Subsequent di-alkylation through treatment with n-butyl lithium, potassium t-butoxide and 1-bromodecane gave $\mathbf{T h}_{\mathbf{3}}(\mathbf{1 0})$ [48].

The terthiophene analogues incorporating oxadiazole and thiadiazole were synthesized according to Scheme 1. 2-Decylthiophene was prepared from thiophene according to literature methods [74]. A carboxylic acid group was installed in the 5-position by treatment with n-butyl lithium, followed by carbon dioxide [75]; this acid was then treated with thionyl chloride to produce the acid chloride in situ, two equivalents of which were condensed in the presence of hydrazine hydrate and triethylamine 
to give $\mathbf{1}$ [76]. The ring-closing of $\mathbf{1}$ in the presence thionyl chloride produced Th-Oxd-Th(10) [76]. Alternatively, treatment of $\mathbf{1}$ with Lawesson's reagent produced Th-Thd-Th(10) [76].

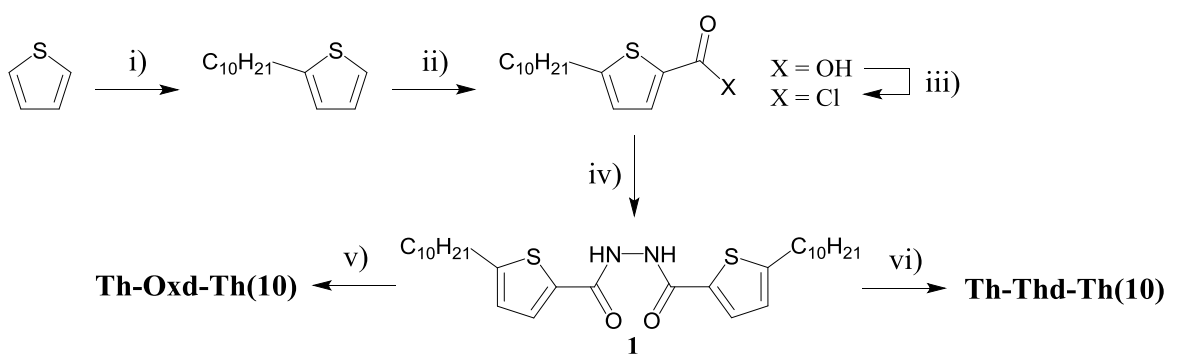

Scheme 1. Synthetic route to Th-Oxd-Th(10) and Th-Thd-Th(10). (i) (1) n-BuLi, THF, $-78{ }^{\circ} \mathrm{C}$; (2) $\mathrm{C}_{10} \mathrm{H}_{21} \mathrm{Br}, \mathrm{RT}, 81 \%$; (ii) (1) $\mathrm{n}-\mathrm{BuLi}, \mathrm{THF},-78{ }^{\circ} \mathrm{C}$; (2) $\mathrm{CO}_{2}, \mathrm{RT}, 69 \%$; (iii) $\mathrm{SOCl}_{2}$, reflux; (iv) $\mathrm{H}_{2} \mathrm{NNH}_{2} \cdot \mathrm{H}_{2} \mathrm{O}, \mathrm{Et}_{3} \mathrm{~N}, \mathrm{NMP}, \mathrm{RT}, 37 \%$; (v) $\mathrm{SOCl}_{2}$, reflux, 64\%; (vi) Lawesson's reagent, toluene, reflux, $51 \%$.

The alternative 2-step route shown in Scheme 2 was adopted for the synthesis of the remaining Th-Thd-Th $(n)$ derivatives. The Th-Thd-Th parent compound was prepared in a one-pot reaction of 2-thiophenecarboxaldehyde, hydrazine hydrate, and sulfur in a high pressure vessel according to literature reports [77]. Di-alkylation of this intermediate by deprotonation with n-butyl lithium and potassium t-butoxide, followed by the appropriate 1-bromoalkane afforded the final target compounds.

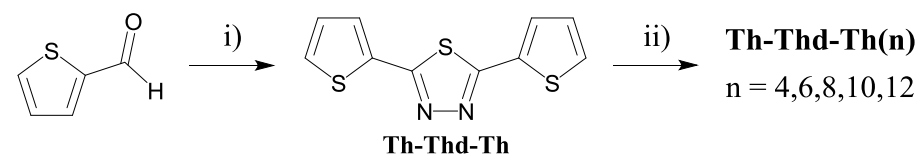

Scheme 2. Synthetic route used to prepare the complete series of Th-Thd-Th(n) derivatives $(n=4,6$, 8,12 ); (i) $\mathrm{H}_{2} \mathrm{NNH}_{2} \cdot \mathrm{H}_{2} \mathrm{O}$, sulfur, propanol, $150{ }^{\circ} \mathrm{C}$, high pressure, $88 \%$; (ii) (1) n-BuLi, t-BuOK, THF, $-78{ }^{\circ} \mathrm{C}$; (2) $\mathrm{C}_{10} \mathrm{H}_{21} \mathrm{Br}, \mathrm{RT}, 29 \%-69 \%$.

\subsection{Phase Behaviour}

The liquid crystal and solid-state self-assembly of all compounds were investigated by differential scanning calorimetry (DSC), polarized optical microscopy (POM), variable temperature powder $\mathrm{x}$-ray diffraction (VT-pXRD), and single crystal x-ray diffraction (SC-XRD), the results of which are summarized in Table 1. The complete data is available in Figures S1-25 and Tables S1-4 in the Supplementary Materials. In all cases, this phase behaviour was observed upon repeated heating/cooling cycles. TGA analysis (see Supplementary Materials) indicated that no decomposition occurs for any of compound studied below $250^{\circ} \mathrm{C}$.

$\mathrm{Th}_{3}(\mathbf{1 0})$ was reported to form a narrow $\mathrm{SmC}$ phase from $92-95^{\circ} \mathrm{C}$, a SmF phase from $71-92{ }^{\circ} \mathrm{C}$, and a lamellar crystalline solid at lower temperatures [50]. Our results are in agreement with these reports. POM images obtained around the clearing point show the emergence of schlieren and focal-conic fan textures (Figure 2a,b, respectively) from the isotropic liquid (dark regions), consistent with a SmC phase. We were unable to corroborate this assignment by XRD due to the narrow temperature range of this phase.

Further cooling leads to a second fluid phase that exhibits POM textures (Figure 2c) resembling those of the overlying SmC phase, indicating that similar ordering is maintained. The XRD pattern (Figure S6) exhibits a sharp low-angle peak, assigned to $d_{001}$ of a lamellar phase. The layer spacing (36.0 $\AA$ ) is slightly smaller than the calculated molecular length $(39.1 \AA)$, which suggests a tilted phase, but could also result from interdigitation of the alkyl chains. The peak in the wide-angle region is sharper than that of typical fluid smectic phases such as SmA and SmC, consistent with an ordered lamellar phase such as SmF or SmI [78], both of which are common underlying phases for the SmC 
phase. Although we cannot rule out the formation of orthogonal phases based on the available data, our assignment of SmC and SmF phases is consistent with previous reports [50-55].

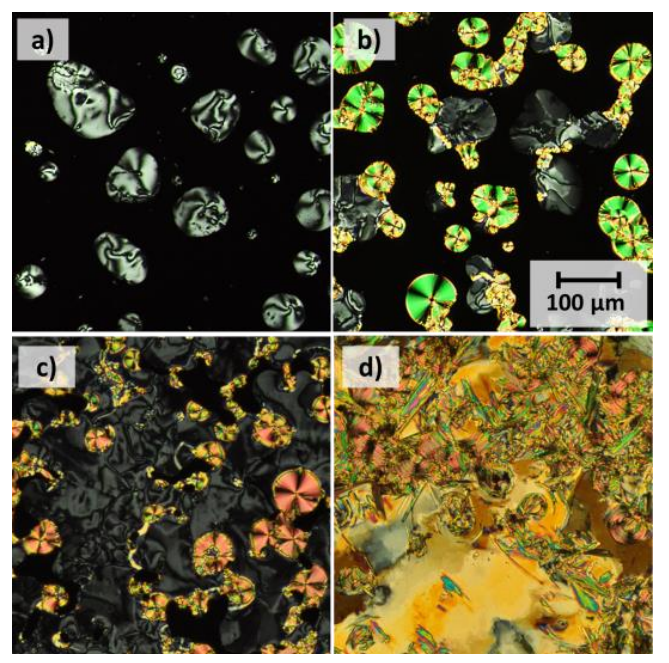

Figure 2. POM of $\mathbf{T h}_{\mathbf{3}}(\mathbf{1 0})$ showing schlieren (a) and focal-conic (b) textures of the SmC phase at $93.5^{\circ} \mathrm{C}$, modified textures of the $\mathrm{SmF}$ phase at $91.5^{\circ} \mathrm{C}(\mathrm{c})$, and changes upon cooling to the crystalline phase at $65.0{ }^{\circ} \mathrm{C}(\mathbf{d})$.

The transition into the next phase upon cooling is accompanied by dramatic changes in the POM, with the schlieren regions becoming bright and the fan textures distorted by striations (Figure 2d). The lack of fluidity under mechanical shearing confirms that this phase is a solid. No further changes are observed by POM upon cooling to room temperature. The room temperature XRD of this compound consists of a low-angle $\mathrm{d}_{001}$ peak along with higher order diffractions demonstrating that layered order is maintained; multiple sharp, intense peaks in the wide-angle region indicate increased intra-layer ordering (Figure S6).

In contrast, Th-Oxd-Th(10) was not liquid crystalline. The POM images of the phase immediately below the isotropic liquid display needle-like crystallites that do not shear (Figure S1). The XRD of this phase exhibits numerous sharp, low intensity peaks (Figure S7), consistent with a crystalline solid phase.

The DSC of Th-Thd-Th(10) contains three peaks that are observed on repeated heating and cooling cycles (Figure S17). POM images of the high temperature phase obtained on cooling from the isotropic liquid are shown in Figure 3a. As observed for $\mathrm{Th}_{\mathbf{3}}(\mathbf{1 0})$, the coexistence of these focal-conic fan and schlieren textures is characteristic of a SmC LC phase. This assignment was confirmed by XRD (Figure $4 \mathrm{a}$ ). In the small angle region, a sharp $\mathrm{d}_{001}$ peak and a low intensity $\mathrm{d}_{002}$ diffraction can be identified, indicative of lamellar packing with a d-spacing of $30.1 \AA$. This layer spacing is considerably shorter than the calculated molecular length of $40.0 \AA$, suggesting that the molecules are tilted within the layers, although interdigitation may also account for a portion of this discrepancy. In the wide angle region, the broad, low intensity peak at a d-spacing of $4.37 \AA$ is ascribed to the alkyl halo commonly observed for disordered smectic phases. 


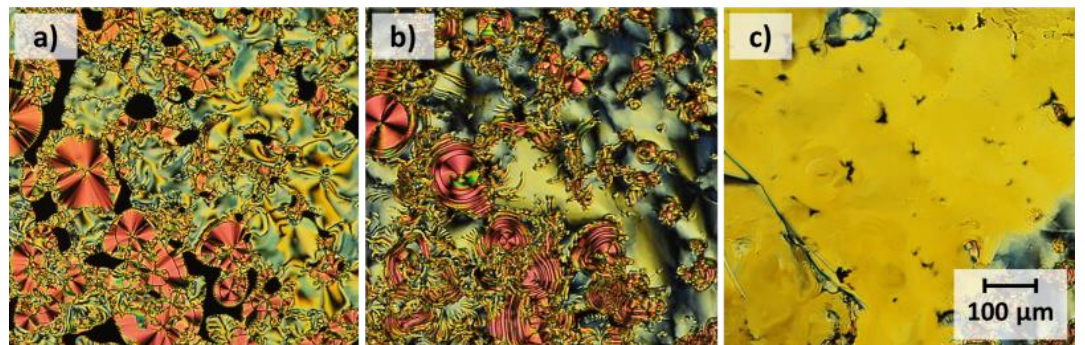

Figure 3. POM of Th-Thd-Th(10) showing schlieren and focal-conic textures of the SmC phase at $125.0^{\circ} \mathrm{C}(\mathbf{a})$, modified textures of the $\mathrm{CrJ}$ phase at $91.0^{\circ} \mathrm{C}(\mathbf{b})$, and changes upon cooling to the crystalline phase at $79.0^{\circ} \mathrm{C}(\mathrm{c})$.
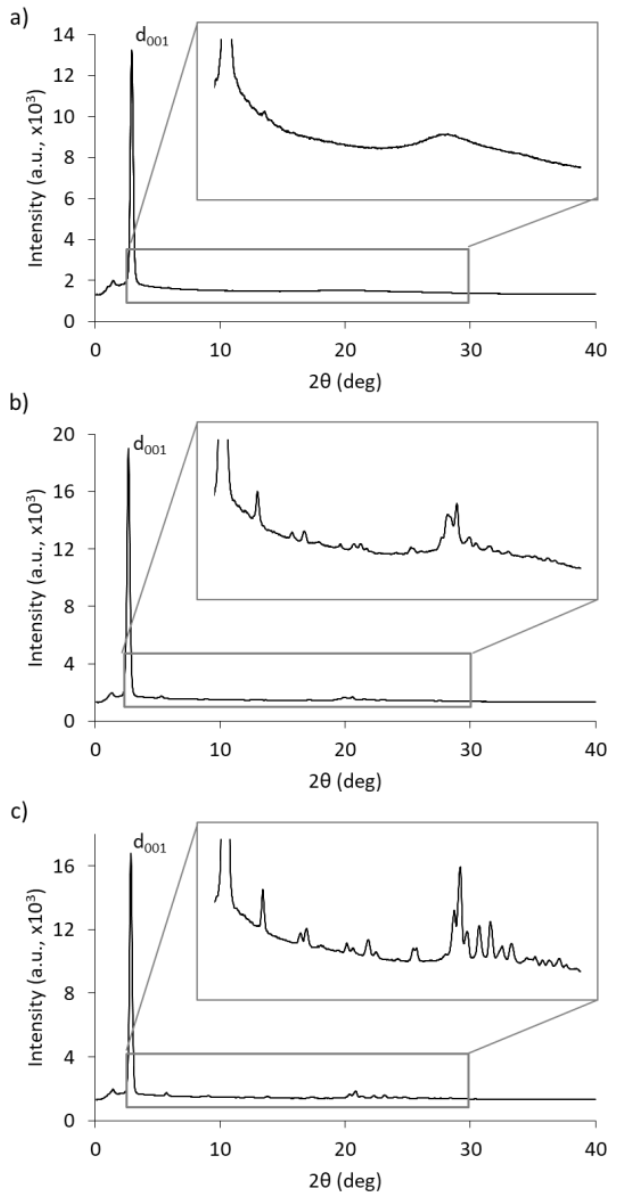

Figure 4. XRD of Th-Thd-Th(10) at $126^{\circ} \mathrm{C}$, in the $\mathrm{SmC}$ phase (a); at $88^{\circ} \mathrm{C}$, in the $\mathrm{CrJ}$ phase (b); and at $25^{\circ} \mathrm{C}$, in the crystalline phase (c).

Upon further cooling below the transition at $91^{\circ} \mathrm{C}$, the POM textures develop striations across the fan-shaped regions, and the schlieren patterns blur into a mosaic texture (Figure $3 \mathrm{~b}$ ). These changes are commonly associated with the formation of more highly ordered smectic phases $[47,48,79,80]$, which is further supported by the XRD data (Figure $4 \mathrm{~b}$ ). The lamellar $\mathrm{d}_{001}, \mathrm{~d}_{002}$ and $\mathrm{d}_{003}$ peaks become more pronounced, signifying an increase in long-range layer ordering, and the layer spacing increases to $33.3 \AA$, from $30.1 \AA$ in the SmC phase. In the wide angle region, several sharp peaks appear, associated with an increase in intra-layer ordering. This XRD pattern is more consistent with an ordered lamellar soft crystal G or J phase than SmF/I phases (see above). Single crystal studies discussed below indicate that the orientation of the molecules tilt towards the apex of the hexagonal intra-layer packing, and thus this phase was assigned as a CrJ phase. 
Further cooling of this sample below $82{ }^{\circ} \mathrm{C}$ results in the loss of the preceding POM textures to give relatively featureless domains that are maintained down to room temperature (Figure 3c). The XRD of this phase is shown in Figure $4 \mathrm{c}$. The sharp low-angle $\mathrm{d}_{001}, \mathrm{~d}_{002}$, and $\mathrm{d}_{003}$ peaks demonstrate that the lamellar order is maintained. The pattern in the wide-angle region becomes even more complex with higher intensity peaks corresponding to increased intra-layer order, leading to the assignment of this room temperature phase as a highly ordered lamellar crystalline phase $(\mathrm{Cr})$.

Prompted by the observation of LC properties of Th-Thd-Th(10), we extended our study to derivatives with varying terminal chain lengths $(n)$ for comparison to the literature $\mathbf{T h}_{3}(n)$ series. The phase transitions of all compounds, as determined by DSC (Figures S14-18), are listed in Table 1. The POM and XRD results are shown in Figures S2-5 and Figures S8-11 respectively.

Table 1. Phase behaviour of the compounds studied.

\begin{tabular}{|c|c|c|c|c|c|c|c|c|c|}
\hline Compound & Phase $^{a}$ & $\mathrm{~T}_{\mathrm{t}}{ }^{/{ }^{\circ} \mathrm{C}\left(\Delta \mathrm{H} / \mathrm{kJ} \mathrm{mol}{ }^{-1}\right)^{\mathrm{b}}}$ & Phase $^{a}$ & $\mathrm{~T}_{\mathrm{t}} /{ }^{\circ} \mathrm{C}\left(\Delta \mathrm{H} / \mathrm{kJ} \mathrm{mol}{ }^{-1}\right)^{\mathrm{b}}$ & Phase $^{a}$ & $\mathrm{~T}_{\mathrm{t}}{\stackrel{ }{ }{ }^{\prime} \mathrm{C}\left(\Delta \mathrm{H} / \mathrm{kJ} \mathrm{mol}{ }^{-1}\right)^{\mathrm{b}}}^{=}$ & Phase $^{a}$ & $\mathrm{~T}_{\mathrm{t}}{ }^{\prime} \stackrel{\mathrm{C}\left(\Delta \mathrm{H} / \mathrm{kJ} \mathrm{mol}{ }^{-1}\right)^{\mathrm{b}}}{=}$ & Phase $^{a}$ \\
\hline $\mathrm{Th}_{3}(\mathbf{1 0})$ & $\mathrm{Cr}^{\prime}$ & $\frac{48.1(1.55)}{=15.7(-1.42)}$ & $\mathrm{Cr}$ & $\frac{71.5(30.5)}{65.7(-33.0)}$ & $\mathrm{SmF}$ & $\frac{93.8\left(18.4^{*}\right)}{93.1\left(-19.4^{*}\right)}$ & $\mathrm{SmC}$ & $\frac{94.7\left(18.4^{*}\right)}{93.6\left(-19.4^{*}\right)}$ & I \\
\hline Th-Oxd-Th(10) & & & $\mathrm{Cr}^{\prime \prime}$ & $\frac{62.2(14.9)}{58.7(-13.8)}$ & $\mathrm{Cr}^{\prime}$ & $\frac{68.0(2.31)}{66.2(-2.80)}$ & $\mathrm{Cr}$ & $\frac{77.4(2.5)}{7.3 .3(-32.3)}$ & I \\
\hline Th-Thd-Th(4) & & & $\mathrm{Cr}^{\prime \prime}$ & $\longdiv { 2 8 . 1 ( - 2 . 2 1 ) }$ & $\mathrm{Cr}^{\prime}$ & $\frac{55.7(15.4)}{34.6(-4.82)}$ & $\mathrm{Cr}$ & $\frac{101.2(14.2)}{96.9(-14.5)}$ & I \\
\hline Th-Thd-Th(6) & & & & & $\mathrm{CrJ}$ & $\frac{94.3(6.20)}{83.2(-6.66)}$ & $\mathrm{SmC}$ & $\frac{114.7(4.65)}{113.5(-4.77)}$ & I \\
\hline Th-Thd-Th(8) & & & $\mathrm{Cr}$ & $\frac{92.4\left(19.8^{*}\right)}{77.4(-11.7)}$ & $\mathrm{CrJ}$ & $\frac{95.0\left(19.8^{*}\right)}{89.0(-11.0)}$ & $\mathrm{SmC}$ & $\frac{129.1(12.9)}{127.9(-13.1)}$ & I \\
\hline Th-Thd-Th(10) & & & $\mathrm{Cr}$ & $\frac{87.1(8.44)}{79.8(-10.0)}$ & $\mathrm{CrJ}$ & $\frac{96.4(11.3)}{961.7(-12.1)}$ & $\mathrm{SmC}$ & $\frac{132.6(15.2)}{131.4(-15.9)}$ & I \\
\hline Th-Thd-Th(12) & $\mathrm{Cr}$ & $\frac{93.5(11.1)}{83.8(-12.5)}$ & $\mathrm{CrJ}$ & $\frac{99.5(12.9)}{96.5(-14.0)}$ & SmI & $\frac{103.9(0.50)}{103.7(-0.96)}$ & $\mathrm{SmC}$ & $\frac{132.5(18.3)}{131.7(-18.8)}$ & I \\
\hline
\end{tabular}

a as identified by POM and XRD, $\mathrm{Cr}=$ crystalline, $\mathrm{Sm}$ = smectic, $\mathrm{I}=$ isotropic, see discussion for details; ${ }^{\mathrm{b}}$ transition temperatures and enthalpies determined by DSC at a scan rate $=10^{\circ} \mathrm{C} / \mathrm{min}$, upon heating/cooling on top/bottom respectively; ${ }^{*}$ combined enthalpy from overlapping peaks.

The shortest chain length derivative, terminated in butyl groups, is not liquid crystalline, but exhibits several polymorphic crystalline states. POM images of Th-Thd-Th(4) obtained on cooling from the isotropic liquid display a rigid, needle-like crystalline texture, and the XRD consists of numerous sharp, low intensity peaks.

At intermediate chain lengths, LC behaviour similar to that of Th-Thd-Th(10) is observed. The derivatives with $n=6$ and 8 exhibit a SmC phase immediately below the isotropic liquid, as evidenced by characteristic schlieren and fan-shaped textures in the POM and XRD patterns consisting of a sharp low-angle $\mathrm{d}_{001}$ peak and a broad, low intensity alkyl halo in the wide-angle region. At the next phase transition, the POM images transform into mosaic and striated fan textures and the XRD shows higher order $\mathrm{d}_{00 n}$ diffractions in the low-angle region and additional sharp peaks at wider angles. This phase was identified as a CrJ phase, due to the similarities to observations for Th-Thd-Th(10). In the case of Th-Thd-Th(6), this phase is maintained down to room temperature, whereas Th-Thd-Th(8) exhibits an additional room temperature lamellar crystalline phase similar to that of Th-Thd-Th(10).

POM and XRD studies indicate that Th-Thd-Th(12) also forms SmC and CrJ phases. However, the DSC of this compound indicates the presence of an additional intermediate phase. The minimal changes in the POM textures and the low enthalpy change of the associated DSC peak suggest that this intermediate phase is similar to the preceding SmC phase. This is supported by the corresponding XRD pattern, which consists of a sharp $\mathrm{d}_{001}$ peak in the low-angle region and a peak of increased intensity and sharpness compared to the SmC phase at wider angles. These results, which are similar to those described for $\mathrm{Th}_{\mathbf{3}}(\mathbf{1 0})$ above, are consistent with $\mathrm{SmF} / \mathrm{I}$ phases. This phase is tentatively assigned as a SmI LC, based on our more detailed analysis of Th-Thd-Th(10). Like Th-Thd-Th(8) 
and Th-Thd-Th(10), this dodecyl derivative exhibits a room temperature lamellar phase; the XRD patterns and POM textures of this phase remained unchanged for over a week, suggesting that it is thermodynamically stable. Similar results were also observed for the room temperature phases of the $n=6,8$, and 10 derivatives.

The persistence length of the layer ordering can be estimated based on the Debye-Scherrer equation applied to the $d_{001}$ peak in the XRD. The resulting correlation lengths of $\mathbf{T h}_{\mathbf{3}}(\mathbf{1 0})$ in the $\mathrm{SmF}$ and $\mathrm{Cr}$ phases are 7 and 8 layers ( 26 and $27 \mathrm{~nm}$ ), respectively. Those of Th-Thd-Th(10) in the SmC, CrJ, and $\mathrm{Cr}$ phases are estimated to be between 10-11 layers (31-34 nm), suggesting that the thiadiazole derivatives tend to exhibit more long range lamellar order than their terthiophene analogues.

A comparison between the phase behavior of $\operatorname{Th}-\mathrm{Thd}-\mathrm{Th}(n)$ derivatives and their $\mathrm{Th}_{3}(n)$ analogues [50] $(n=6,8,10)$ is shown in Figure 5. $\mathbf{T h}_{\mathbf{3}}(\mathbf{4})$ and $\mathbf{T h}_{\mathbf{3}}(\mathbf{1 2})$ were excluded from this analysis since reliable phase assignments are not available for either compound. Both series show a propensity to form layered structures, with SmC phases observed at higher temperatures in most cases, and lamellar crystalline phases formed at room temperature. With the exception of $\mathbf{T h}_{\mathbf{3}}(\mathbf{1 0})$, compounds in both series exhibit soft crystalline G/J phases. The $\mathbf{T h}_{\mathbf{3}}(\mathbf{1 0})$ and $\mathbf{T h}_{\mathbf{3}}(\mathbf{8})$ derivatives exhibit an intermediate SmF phase; this phase is not observed for the Th-Thd-Th(n) derivatives shown, but a similarly ordered SmI phase emerges at longer chain length (Th-Thd-Th(12), see above). Both series exhibit a tendency towards increased phase diversity at longer chain lengths. Liquid crystallinity is not observed for the shortest members of either series (Th-Thd-Th(4) and $\mathbf{T h}_{3}(n)$ for $n \leq 6)$.

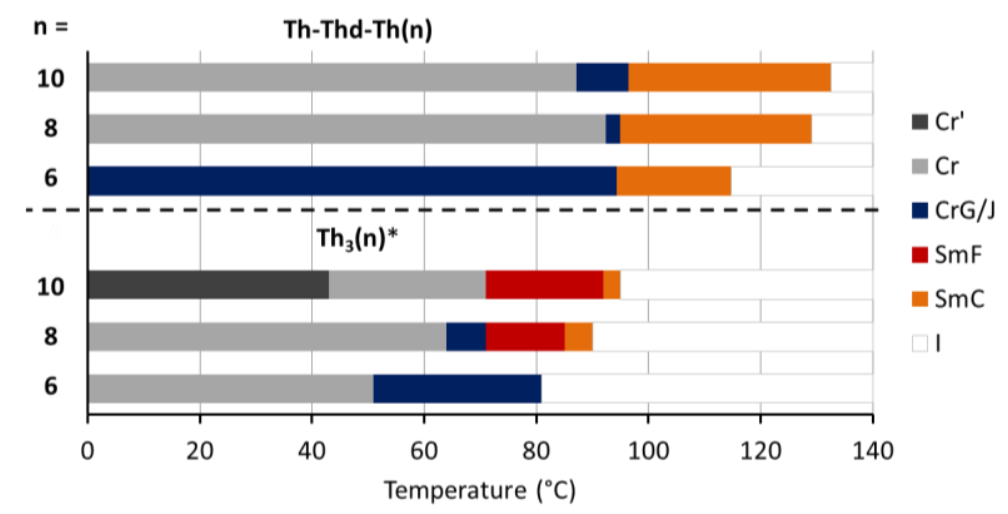

Figure 5. Phase behaviour of $\operatorname{Th}-\operatorname{Thd}-\mathrm{Th}(n)$ (this work) and $\mathbf{T h}_{3}(n)$ ( ${ }^{*}$ literature) [74].

The Th-Thd-Th(n) compounds exhibit SmC phases at higher temperatures and over broader ranges than the corresponding $\mathrm{Th}_{3}(n)$ derivatives. For example, Th-Thd-Th(8) forms a SmC phase over a $34{ }^{\circ} \mathrm{C}$ range $\left(95-129{ }^{\circ} \mathrm{C}\right)$, whereas the $\mathrm{SmC}$ phase of $\mathrm{Th}_{3}(8)$ is stable over only a $5{ }^{\circ} \mathrm{C}$ range $\left(85-90^{\circ} \mathrm{C}\right)$. As film processing from well-oriented but fluid states (e.g., $\mathrm{SmA} / \mathrm{C}$ ) is advantageous for obtaining uniformly aligned samples $[37,58,59]$ and thermal annealing at elevated temperatures has been shown to improve film morphology $[31,48,81]$, the increased SmC phase stabilities of the thiadiazole derivatives make them attractive candidates for device fabrication.

The highly ordered crystalline lamellar phases of $\mathbf{T h}-\mathbf{T h d}-\mathbf{T h}(n)$ are also stable to higher temperatures than those of $\mathrm{Th}_{3}(n)$. For example, the $\mathrm{Cr}$ phase of $\mathrm{Th}-\mathrm{Thd}-\mathrm{Th}(8)$ is maintained up to $92{ }^{\circ} \mathrm{C}$, whereas $\mathrm{Th}_{3}(8)$ melts into a liquid crystal at $71^{\circ} \mathrm{C}$. Charge carrier mobility tends to increase in more highly ordered phases [56-58], and phase transitions lead to discontinuity in performance [82,83]. Higher Cr-Sm transition temperatures such as those found for Th-Thd-Th(n) could therefore facilitate a wider range of operating temperatures and lower the chance of performance degradation due to thermally-induced transitions.

The pronounced differences in phase behaviour between these series in general, and between $\mathrm{Th}_{3}(\mathbf{1 0})$, Th-Thd-Th(10), and Th-Oxd-Th(10) in particular, can be rationalized based on changes in molecular shape and electronics. The density functional theory (DFT) optimized structures, determined 
using B3LYP/6-31G*, (Figure 6) indicate that the bend angle of the molecules, which is largely dictated by the bond angles at the 2- and 5-positions of the central heterocycle are $156^{\circ}, 142^{\circ}$, and $169^{\circ}$ for $\mathbf{T h}_{\mathbf{3}}(\mathbf{1 0})$, Th-Oxd-Th(10), and Th-Thd-Th(10), respectively. Molecular shape is a key determinant for liquid crystallinity, with more linear structures promoting these phases [84-87]. Therefore, the larger angles in $\mathrm{Th}_{\mathbf{3}}(\mathbf{1 0 )}$ and $\mathrm{Th}-\mathrm{Thd}-\mathrm{Th}(\mathbf{1 0 )}$ favor LC phases, whereas the more bent structure of $\mathbf{T h}-\mathrm{Oxd}-\mathrm{Th}(\mathbf{1 0})$ would be detrimental for mesophase formation. This is consistent with previous literature suggesting that thiadiazole derivatives have a greater tendency to exhibit smectic mesophases than oxadiazole analogues [88-91].

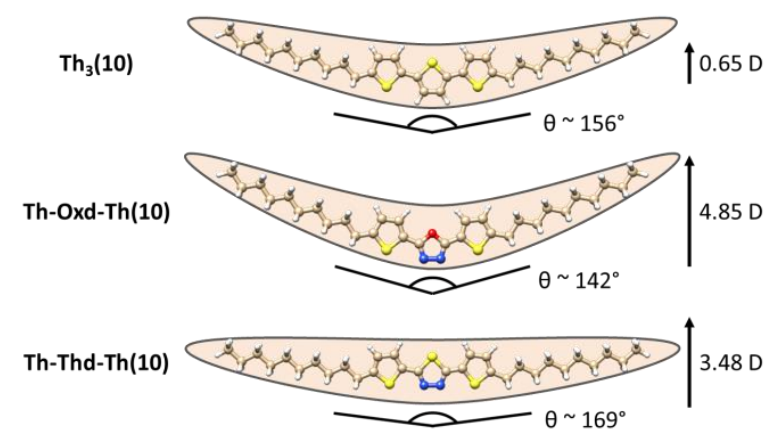

Figure 6. The optimized structures of the compounds studied, showing differences in bend angle, $\theta$, and transverse dipole moment. See Supplementary Materials for calculation details.

The transverse dipole moments, i.e., those perpendicular to the long axis of the molecule, are $0.65 \mathrm{D}, 4.85 \mathrm{D}$, and $3.48 \mathrm{D}$ for $\mathbf{T h}_{\mathbf{3}}(\mathbf{1 0 )}$, Th-Oxd-Th(10), and Th-Thd-Th(10), respectively. Because liquid crystalline self-assembly is strongly influenced by dipole-dipole interactions $[85,92,93]$ the substantially larger dipole of Th-Thd-Th(10) may stabilize its LC phases relative to those of $\mathbf{T h}_{\mathbf{3}}(\mathbf{1 0})$. More broadly, the elevated transition temperatures of Th-Thd-Th $(n)$ compared to the corresponding terthiophenes $\mathbf{T h}_{3}(n)$ can be attributed to a combination of the higher transverse dipole moments and more linear structures of the former series.

In an effort to gain more insight into the solid-state structures of the phases, crystal growth via slow evaporation from a variety of solvents was explored. Suitable single crystals of Th-Thd-Th, Th-Thd-Th(4) and Th-Thd-Th(10) were obtained from acetonitrile or tetrahydrofuran and analyzed by XRD. The single crystal structure of Th-Thd-Th(10) demonstrates lamellar order with significant tilt angle $\left(\sim 32^{\circ}\right.$, Figure 7 a and Figure S19), as well as pseudo-hexagonal packing within each layer (Figure 7b), consistent with the phase assignments made by POM and XRD above. The single crystal structure of Th-Thd-Th(4) also shows lamellar order (Figure S21), with one butyl chain extending parallel to the core and the other approximately orthogonal. In contrast, both the decyl chains of Th-Thd-Th(10) extend along the direction of the core. This difference in the orientation of the alkyl chains provides a clue as to why the latter is liquid crystalline but the former is non-mesogenic.

The lamellar order in the crystal structure of Th-Thd-Th(4) is clearly evident in a low angle $\mathrm{d}_{001}$ peak in the corresponding simulated powder diffraction pattern (Figure S25). This peak is not observed in the experimental powder XRD (Figure S11), which is attributed to distinct polymorphs resulting from the different conditions under which the samples were prepared and measured. The simulated and experimental powder XRD patterns of Th-Thd-Th(10) are in good agreement (Figure S25) with some variation in the relative intensities and positions of the wide angle peaks, which likely can be ascribed to the temperature differences between the measurements. 


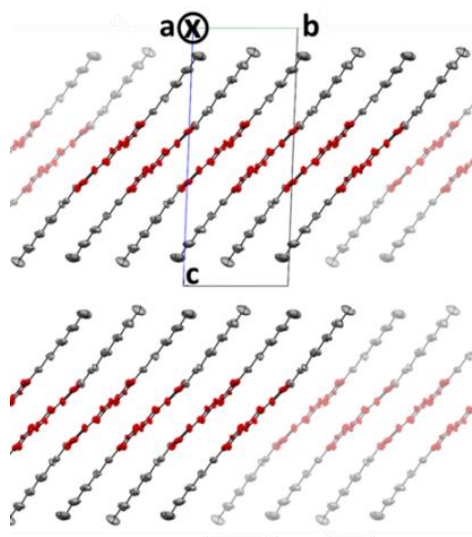

(a)

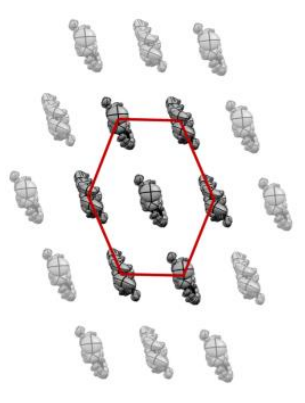

(b)

Figure 7. Crystal structure of Th-Thd-Th(10) showing lamellar order (a) and pseudo-hexagonal intra-layer packing (b). Legend: Alkyl chains in grey, aromatic core in red, hydrogens omitted for clarity.

The crystal structures obtained for the thiadiazole derivatives can also be compared to literature reports of their terthiophene analogues. The crystal structure of $\mathbf{T h}_{\mathbf{3}}(\mathbf{8})$ reported by Lercher et al. [94] (Figure S23) also exhibits lamellar order with pseudo-hexagonal intra-layer packing, in line with our POM and XRD results. Consistent with the DFT models, the crystal structures show that $\mathbf{T h}_{\mathbf{3}}(\mathbf{8})$ is more bent than Th-Thd-Th(10), with angles between the bonds at the 2 and 5 positions of the central heterocycle of $147^{\circ}$ and $157^{\circ}$, respectively (Figure S20). The crystal structures differ with respect to the correlation of molecular orientation from one layer to the next. In Th-Thd-Th(10), each successive layer has the same tilt direction (synclinic), whereas alternating layers exhibit opposing (anticlinic) tilt directions in the structure of $\mathbf{T h}_{\mathbf{3}}(\mathbf{8})$.

Another distinction in the packing motif of the two compounds becomes evident upon closer inspection of the relative orientation of adjacent molecules within a layer. Figure 8a shows that for Th-Thd-Th(10) two molecules pack with their aromatic cores in a face-to-face fashion, with an anti-parallel arrangement. In contrast, molecules of $\mathbf{T h}_{\mathbf{3}}(\mathbf{8})$ orient in a herringbone configuration, with an approximate $55^{\circ}$ angle between the planes of the molecules (Figure 8b). An increased tendency for face-to-face packing is also found in the crystal structures of the unsubstituted Th-Thd-Th core (Figure S22) compared to the analogous terthiophene $\mathbf{T h}_{3}$ (Figure S24) [95]. The latter assumes a herringbone structure with molecules close to $90^{\circ}$ to one another, while the former exhibits a modified herringbone-type configuration composed of co-facially packed pairs of molecules, with adjacent pairs arranged in a herringbone structure. Th-Thd-Th(4) shows a similar co-facial arrangement of adjacent molecules.

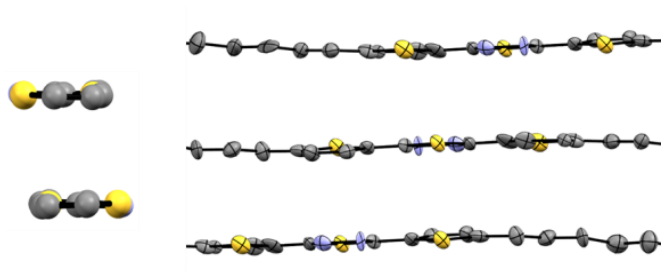

(a)
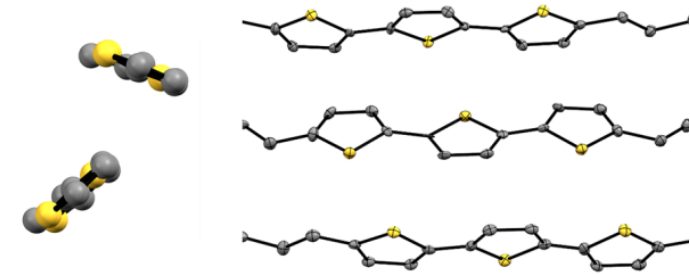

(b)

Figure 8. Packing of adjacent molecules in $\mathbf{T h}-\mathbf{T h d - T h}(\mathbf{1 0})(\mathbf{a})$ and $\mathbf{T h}_{\mathbf{3}}(\mathbf{8})(\mathbf{b})$ as viewed along the long axis of the molecule (left) and the short axis of the molecule (right). Legend: sulphur in yellow, nitrogen in light blue, carbon in grey, hydrogens omitted for clarity. 
The stronger tendency of the thiadiazole derivatives to adopt face-to-face packing can be rationalized based on dipolar interactions. As already noted, DFT calculations indicate that Th-Thd-Th(10) has a much larger transverse dipole moment than $\mathbf{T h}_{\mathbf{3}}(\mathbf{1 0})$, which favours the antiparallel stacked structures observed for the former. Similar effects have been noted in the self-assembly of discotic mesogens [92,93]. As a result, Th-Thd-Th(10) displays close intermolecular contacts, with a distance of $3.5 \AA$ between the aromatic cores. These differences in the packing present a potential advantage for organic semiconductor applications since charge carrier transport is strongly dependent on close contacts and $\pi-\pi$ overlap between adjacent molecules $[18,96-100]$. The stronger interactions within the layers of the thiadiazole analogues may also cause the increased transition temperatures of their LC and solid-state phases, as discussed above.

\subsection{Molecular Opto-Electronic Properties}

The UV-vis absorption spectra of $\mathrm{Th}_{\mathbf{3}}(\mathbf{1 0})$, Th-Thd-Th(10), and Th-Oxd-Th(10) in chloroform solutions $\left(4 \times 10^{-5} \mathrm{M}\right)$ are shown in Figure 9 a, with the data summarized in Table 2. The line shape and absorptivity values were independent of concentration (Figures S26-28). All three compounds feature a single strong absorption between 300 and $400 \mathrm{~nm}$, with extinction coefficients greater than $25,000 \mathrm{M}^{-1} \cdot \mathrm{cm}^{-1}$. In all cases, these peaks are relatively broad and lack obvious fine vibrational structure, indicating the conformational flexibility of the ground state in solution, which has previously been demonstrated for oligothiophene systems $[101,102]$. The absorption band is blue-shifted on going from $\mathbf{T h}_{\mathbf{3}}(\mathbf{1 0})\left(\lambda_{\max }=367 \mathrm{~nm}\right)$ to Th-Thd-Th(10) $\left(\lambda_{\max }=359 \mathrm{~nm}\right)$ to Th-Oxd-Th(10) $\left(\lambda_{\max }=328 \mathrm{~nm}\right)$. Time-dependent density functional theory (TD-DFT) calculations reproduce the trend and shape of the experimental spectra, with absorption maxima of $383 \mathrm{~nm}(f=1.17), 354 \mathrm{~nm}(f=1.11)$, and $323 \mathrm{~nm}$ $(f=1.07)$ for $\mathbf{T h}_{3}(\mathbf{1 0})$, Th-Thd-Th(10), and Th-Oxd-Th(10), respectively. The TD-DFT results indicate that the observed UV-vis absorptions correspond to $S_{0}$ to $S_{1} / H O M O-L U M O$ transitions from the $\pi$ to $\pi^{*}$ orbitals. The optical band gaps calculated from the absorption onset were estimated to be $2.93,3.04$, and $3.35 \mathrm{eV}$ for $\mathbf{T h}_{\mathbf{3}} \mathbf{( 1 0 )}$, Th-Thd-Th(10), and Th-Oxd-Th(10), respectively.
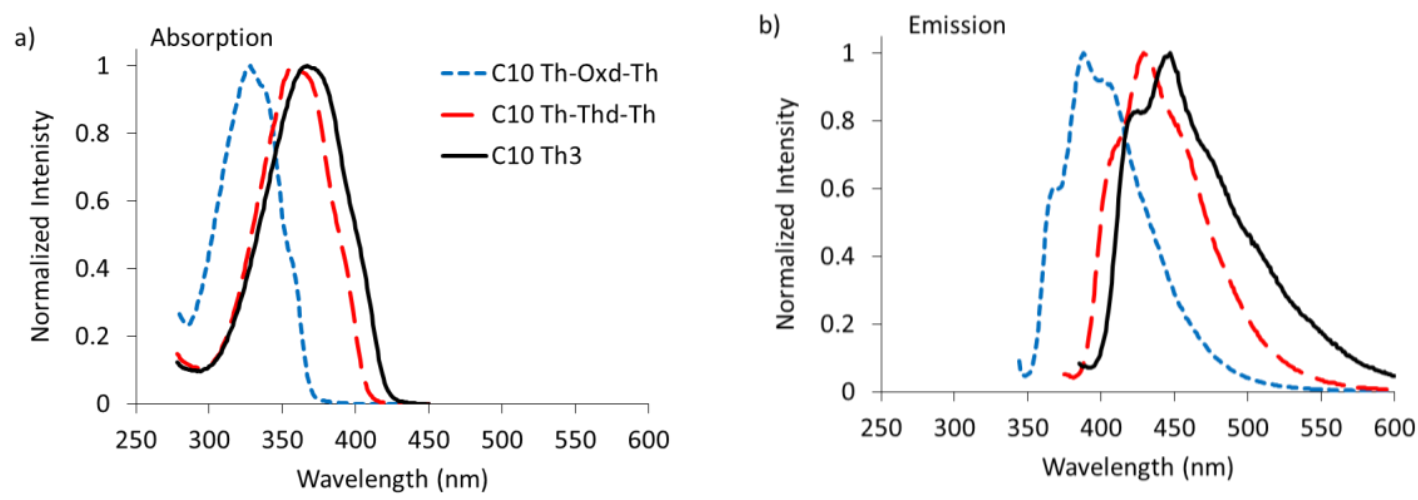

Figure 9. Absorption (a) and emission (b) spectra of $\mathrm{Th}_{\mathbf{3}}(\mathbf{1 0 )}$, Th-Oxd-Th(10) and Th-Thd-Th(10) in $\mathrm{CHCl}_{3}$.

The emission spectra of $\mathbf{T h}_{\mathbf{3}}(\mathbf{1 0 )})$ Th-Thd-Th(10) and Th-Oxd-Th(10) measured in chloroform $\left(10^{-6}-10^{-5} \mathrm{M}\right)$ are shown in Figure $9 \mathrm{~b}$, with the data summarized in Table 2. The excitation spectra recorded match the UV-vis absorption spectra of the respective compounds (Figure S29). The emission spectra were recorded at the wavelength of maximum excitation intensity $\left(\lambda_{e x}^{\max }=340,369\right.$, and $380 \mathrm{~nm}$ for Th-Oxd-Th(10), Th-Thd-Th(10), and $\mathrm{Th}_{3}(\mathbf{1 0})$ respectively). All three compounds exhibit strong emission between $350-550 \mathrm{~nm}$, with moderate $45-65 \mathrm{~nm}$ Stokes shifts. In contrast to the absorption spectra, the emission spectra display defined vibronic structure that is ascribed to the quinoidal character of the excited state, as previously reported for thiophene oligomers [101,102]. The fluorescence quantum yield $\left(\Phi_{\mathrm{f}}\right)$ of $\mathbf{T h}_{\mathbf{3}}(\mathbf{1 0 )}$, determined relative to a quinine sulfate standard, was 0.56 . Although this is higher than previously reported values, which range from 0.02 to 0.24 , significant disparities in $\Phi_{\mathrm{f}}$ 
under different experimental conditions are common in the literature [101-103]. Th-Oxd-Th(10) and Th-Thd-Th(10) exhibit similar fluorescence quantum yields of 0.48 and 0.49 , respectively. These spectroscopic studies indicate that both the thiadiazole and oxadiazole derivatives exhibit strong absorption and emission, comparable to the parent terthiophene compound.

Table 2. Summary of the optical properties of the compounds studied.

\begin{tabular}{|c|c|c|c|c|c|c|}
\hline Compound & $\lambda_{a b s}^{\max }(\mathrm{nm})$ & $\left(\mathrm{M}^{-1} \cdot \mathrm{cm}^{\mathcal{E}}\right)$ & $\begin{array}{c}E_{\mathrm{g}} \text { opt a } \\
(\mathrm{eV}) \text { [calc.] }\end{array}$ & $\lambda_{e x}^{\max }(\mathrm{nm})$ & $\lambda_{e m}^{\max }(\mathrm{nm})$ & $\Phi_{f} b$ \\
\hline Th-Oxd-Th(10) & 328 & 28200 & 3.35 [3.26] & 340 & 387 & 0.48 \\
\hline Th-Thd-Th(10) & 359 & 26800 & $3.04[2.94]$ & 369 & 430 & 0.49 \\
\hline $\mathrm{Th}_{3}(\mathbf{1 0 )}$ & 367 & 25900 & 2.93 [2.67] & 380 & 443 & 0.56 \\
\hline
\end{tabular}

${ }^{\mathrm{a}}$ Optical bandgap, estimated by $E_{\mathrm{g}}=h \mathrm{c} / \lambda_{\text {abs }}^{\text {onst }}$, calc. value obtained from TD-DFT (CAM-B3LYP/TZVP/pcm);

${ }^{\mathrm{b}}$ Relative to quinine sulfate standard $\left(\Phi_{\mathrm{f}}=0.54\right)$ in $0.1 \mathrm{M} \mathrm{H}_{2} \mathrm{SO}_{4}$.

The cyclic voltammograms of select compounds are shown in Figure 10, with the data summarized in Table 3. Th-Thd-Th(6) exhibits a quasi-reversible wave at $-2.41 \mathrm{~V}$, which we assign to a stable one-electron reduction process, as well as an irreversible oxidation at $1.18 \mathrm{~V}$. Based on these reduction and oxidation waves measured relative to ferrocene, the HOMO and LUMO energy levels of Th-Thd-Th(6) were estimated as -5.98 and $-2.39 \mathrm{eV}$, respectively, giving an electronic band gap of $3.59 \mathrm{eV}$. The corresponding theoretical values from DFT calculations $(\mathrm{HOMO}=-5.54, \mathrm{LUMO}=-1.90$ $\mathrm{eV}$, band gap $=3.64 \mathrm{eV}$ ) are in reasonable agreement with the experimental numbers; the deviations are within the range reported for systems such as $\mathbf{T h}_{\mathbf{3}}(\mathbf{6})$ (see Table 3). The discrepancy between the electronic band gap $(3.59 \mathrm{eV})$ and the optical gap $(3.04 \mathrm{eV})$ yield an approximate exciton binding energy of $0.55 \mathrm{eV}$ [104].

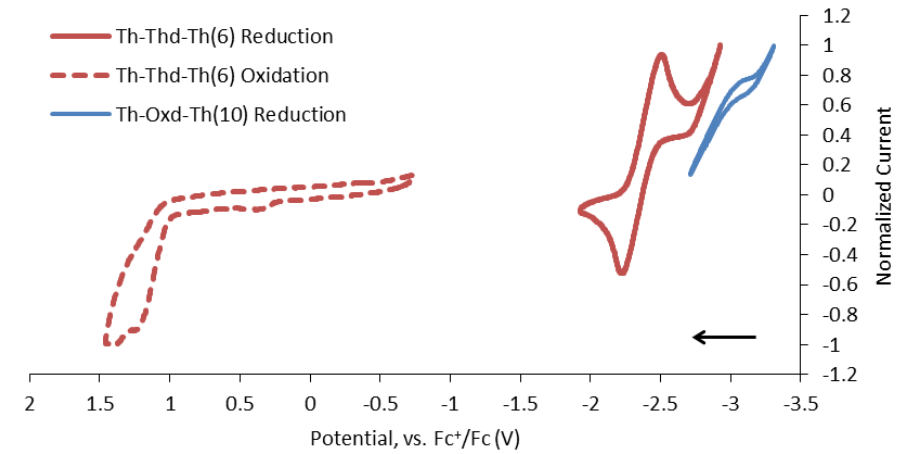

Figure 10. Cyclic voltammograms of $1.0 \mathrm{mM}$ solutions showing reduction of Th-Thd-Th(6) (red) and Th-Oxd-Th(10) (blue) in THF with 0.1 M TBAP supporting electrolyte and oxidation of Th-Thd-Th(6) (red, dotted) in MeCN with 0.1 M TBAF supporting electrolyte.

Th-Oxd-Th(10) displays a wave at $-3.11 \mathrm{~V}$ which gives a corresponding LUMO energy of $-1.69 \mathrm{eV}$, consistent with the DFT predicted value of $-1.62 \mathrm{eV}$. The experimental reduction wave is irreversible, indicating that the reduced form of this compound is unstable. The oxidation wave of this compound could not be recorded due to a combination of low solubility and limitations imposed by the potential windows of the solvents.

The experimental and theoretical results show good agreement with the observed trend in the band gap, which was found to increase from $\operatorname{Th}_{3}(n)$ to $\mathbf{T h}-\operatorname{Thd}-\mathrm{Th}(n)$ to Th-Oxd-Th$(n)$. In principle, we had anticipated the introduction of electron-poor thiadiazole and oxadiazole acceptors to decrease the band gap by lowering the LUMO level. However, experimentally, the reduction potential was found to increase successively from $\operatorname{Th}_{3}(n)$ to $\mathrm{Th}-\mathrm{Thd}-\mathrm{Th}(n)$ to Th-Oxd-Th(n). This is likely a consequence of decreased conjugation between the aromatic rings upon introduction of the thiadiazole or oxadiazole heterocycles, as has previously been demonstrated for mixed-ring oligomers [101,105,106]. We do 
not expect appreciable differences in these values for other homologs in this series since the length of terminal alkyl chains has a minimal impact on the opto-electronic properties [107,108], and DFT shows the electron distribution of the HOMO and LUMO molecular orbitals is concentrated on the aromatic rings (Figure S37).

\section{Conclusions}

In the present work, we examined the effects of replacing the central thiophene of liquid crystalline terthiophenes with either an oxadiazole or thiadiazole ring. This study revealed the pronounced impact of the central heterocycle on the LC properties of these systems. $\mathbf{T h}_{\mathbf{3}} \mathbf{( 1 0 )}$ forms SmC, $\mathrm{SmF}$, as well as room temperature lamellar crystalline phases. Th-Oxd-Th(10) does not display any LC phases but only polymorphic crystalline states. Th-Thd-Th(10) forms SmC, CrJ, and room temperature lamellar crystalline phases. All three classes of compound displayed strong absorption in the ultraviolet region and strong emission in the visible region, with band gaps between 3-3.5 eV.

We postulate that the pronounced differences in LC and solid-state self-assembly arise primarily due to the variation in bend angle and transverse dipole moment among the compounds, as corroborated by single crystal structures and DFT modelling studies. Compared to $\mathbf{T h}_{3}(n)$, the Th-Thd-Th(n) analogs exhibit SmC phases at higher temperatures and over broader ranges, maintain highly ordered lamellar phases to higher temperatures, possess longer correlation lengths of the lamellar order in the smectic phases, and display an increased tendency for molecules to assume face-to-face packing. In light of these differences, Th-Thd-Th(n) demonstrates potential as an organic semiconductor. Future studies will examine the performance of these materials in thin-film transistor (TFT) devices.

\section{Experimental Part}

\subsection{Materials and Methods}

All solvents used were reagent grade. 1-Bromooctane was purchased from TCI America. Triethylamine was purchased from Anachemia. All other reagents were purchased from Sigma-Aldrich. All reagents were used as received without further purification. Column chromatography was performed on silica gel 60 (230-400 mesh) purchased from Silicyle Inc. $\mathrm{CDCl}_{3}$ was obtained from Cambridge Isotope Laboratories Inc.

$400 \mathrm{MHz}{ }^{1} \mathrm{H}$ NMR spectra were obtained on a Bruker AMX-400 $400 \mathrm{MHz}$ NMR spectrometer. $500 \mathrm{MHz}{ }^{1} \mathrm{H}$ and $125 \mathrm{MHz}{ }^{13} \mathrm{C}$ NMR spectra were obtained on a Varian AS500 Unity Inova $500 \mathrm{MHz}$ NMR spectrometer. High resolution mass spectrometry was carried out on a Bruker micrOTOF II LC/MS (electrospray ionization, $\mathrm{ESI}^{+}$) by Nonka Sevova at Notre Dame Mass Spectrometry and Proteomics facility. Phase transition temperatures and enthalpies were determined using differential scanning calorimetry (DSC) on a TA Instruments DSC Q2000 equipped with a TA Instruments Refrigerated Cooling System 90 , heating and cooling at a rate of $10^{\circ} \mathrm{C} \mathrm{min}-1$. Thermogravimetric analysis was carried out on a Shimadzu TGA-50 with a heating rate of $2{ }^{\circ} \mathrm{C}$ per minute. Polarised optical microscopy was carried out using an Olympus BX50 microscope equipped with a Linkam LTS350 heating stage. X-ray scattering experiments were conducted using a Rigaku R-Axis Rapid diffractometer equipped with an in-house built temperature controller [109]. Single crystal x-ray diffraction data was collected on a Bruker Smart instrument equipped with an APEX II CCD area detector fixed at a distance from the crystal and a $\mathrm{Cu} \mathrm{K} \alpha$ fine focus sealed tube $(\lambda=1.54178 \AA$ ) operated at $1.5 \mathrm{~kW}(45 \mathrm{kV}$, $0.65 \mathrm{~mA}$ ), filtered with a graphite monochromator. The temperature was regulated using an Oxford Cryosystems Cryostream. UV-vis absorption spectroscopy was performed using a Varian Cary 300 Bio Spectrometer. Fluorescence measurements were performed using a Photon Technologies International (PTI) Quantamaster spectrofluorometer. Cyclic voltammetry scans were performed on a PAR-263A potentiometer with a glassy carbon working electrode, platinum counter electrode and silver wire reference electrode using $1.0 \mathrm{mM}$ analyte solutions, $0.1 \mathrm{M}$ supporting electrolyte, and $\mathrm{Fc} / \mathrm{Fc}^{+}$ internal reference. Unconstrained DFT geometry optimization of all molecules was carried out at the 
B3LYP/6-31G* [110-115] level in Gaussian 1 [116], and time-dependent (TD-DFT) [117,118] calculations were performed using CAM-B3LYP/TZVP [119-123] in Gaussian 16 [116]. Further method details are given in the Supplementary Materials.

Table 3. Summary of the electrochemical properties of Th-Oxd-Th(10) and Th-Thd-Th(6) along with literature data for $\mathrm{Th}_{3}(\mathbf{6})$.

\begin{tabular}{|c|c|c|c|c|c|c|}
\hline \multirow{2}{*}{ Compound } & \multirow{2}{*}{$\begin{array}{c}\text { Oxidation (V) } \\
E_{1}^{1 / 2}\end{array}$} & \multirow{2}{*}{$\frac{\text { Reduction (V) }}{E_{1}^{1 / 2}}$} & \multicolumn{2}{|c|}{ Energy Levels (eV) [calc.] } & \multicolumn{2}{|c|}{ Band Gap (eV) } \\
\hline & & & HOMO $^{a}$ & LUMO $^{\text {b }}$ & $E_{\mathrm{g}} \mathrm{CV} \mathrm{c}$ & $E_{\mathrm{g}}{ }^{\text {calc. } \mathrm{d}}$ \\
\hline Th-Oxd-Th(10) & - & -3.11 & {$[-5.59]$} & $-1.69[-1.62]$ & - & 3.97 \\
\hline Th-Thd-Th(6) & 1.18 & -2.41 & $-5.98[-5.54]$ & $-2.39[-1.90]$ & 3.59 & 3.64 \\
\hline $\mathrm{Th}_{3}(6)^{*}$ & 1.51 & -2.14 & $-5.92[-4.87]$ & $-2.70[-1.52]$ & 3.22 & 3.35 \\
\hline
\end{tabular}

\subsection{Synthesis}

\subsubsection{Precursors and Literature Compounds}

The hydrazide derivative 1 was prepared by adapted literature procedures according to Scheme 1 above [76]. $\mathbf{T h}_{\mathbf{3}} \mathbf{( 1 0 )}$ was prepared via modified literature reactions [73]. The Th-Thd-Th core was prepared under literature conditions as shown in Scheme 2 above [77]. Synthetic details for each of these compounds are given in the Supplementary Materials.

\subsubsection{Th-Oxd-Th(10)}

In a flame-dried $10 \mathrm{~mL}$ three-neck round bottom flask, hydrazide derivative $1(0.12 \mathrm{~g}, 0.23 \mathrm{mmol})$ was dissolved in thionyl chloride $\left(5.0 \mathrm{~mL}\right.$, excess). After two hours of reflux under $\mathrm{N}_{2}$, the solution was cooled to room temperature. Remaining thionyl chloride was removed by rotary evaporation followed by high vacuum overnight. The crude was dissolved in chloroform $(30 \mathrm{~mL})$ and washed with water $(2 \times 30 \mathrm{~mL})$, saturated sodium bicarbonate $(30 \mathrm{~mL})$, saturated sodium thiosulfate $(30 \mathrm{~mL})$, brine $(30 \mathrm{~mL})$ and then dried over magnesium sulfate. Further purification was done by column chromatography on silica treated with $2 \%$ triethylamine using $10 \%$ ethyl acetate in hexanes as the eluent. Recrystallization from ethanol afforded the product as a yellow solid (64\% yield). Analytical data can be found in the Supplementary Materials.

\subsubsection{Th-Thd-Th(10)}

In a flame-dried $25 \mathrm{~mL}$ three-neck round bottom flask, hydrazide derivative $1(0.40 \mathrm{~g}, 0.75 \mathrm{mmol})$ and 2,4-Bis(4-methoxyphenyl)-2,4-dithioxo-1,3,2,4-dithiadiphosphetane (Lawesson reagent, $0.38 \mathrm{~g}$, 1.25 equivalents) were dissolved in toluene $(15 \mathrm{~mL})$. After $24 \mathrm{~h}$ of reflux under $\mathrm{N}_{2}$, the solution was cooled to room temperature. Toluene was removed by rotary evaporation followed by high vacuum overnight. The crude was dissolved in chloroform $(30 \mathrm{~mL})$ and washed with water $(2 \times 30 \mathrm{~mL})$, saturated sodium bicarbonate $(30 \mathrm{~mL})$, saturated sodium thiosulfate $(30 \mathrm{~mL})$, brine $(30 \mathrm{~mL})$ and then dried over magnesium sulfate. Further purification was done by column chromatography on silica treated with $2 \%$ triethylamine using $10 \%$ ethyl acetate in hexanes as the eluent. Recrystallization from ethanol afforded the product as an orange solid ( $51 \%$ yield). Analytical data can be found in the Supplementary Materials.

\subsubsection{General procedure for Th-Thd-Th( $n)$ Derivatives}

A flame-dried $50 \mathrm{~mL}$ three-neck round bottom flask was charged with Th-Thd-Th core $(0.25 \mathrm{~g}$, $1.0 \mathrm{mmol}$ ) and cycled between high vacuum and $\mathrm{N}_{2}$ atmosphere three times. Dry THF ( $\left.25 \mathrm{~mL}\right)$ was added by cannula and the solution was cooled to around $-78{ }^{\circ} \mathrm{C}$ prior to the drop-wise addition 
of n-butyllithium solution (2.5 M, 2.5 equivalents). After stirring for $30 \mathrm{~min}$, the appropriate alkyl bromide, $\mathrm{C}_{n} \mathrm{H}_{2 n+1} \mathrm{Br}$, (4.0 equivalents) was added in one portion. This mixture was warmed to room temperature and stirred overnight. The reaction was quenched with $10 \% \mathrm{HCl}(25 \mathrm{~mL})$ and extracted with diethyl ether $(3 \times 30 \mathrm{~mL})$. The combined organic fractions were washed with saturated sodium thiosulfate $(2 \times 80 \mathrm{~mL})$, then water $(100 \mathrm{~mL})$ and dried over magnesium sulfate. Further purification was done by column chromatography on silica using a gradient from $2 \%$ to $10 \%$ of ethyl acetate in hexanes as the eluent. Recrystallization from hexanes afforded the product as a light orange solid (29\%-69\% yield). Analytical data can be found in the Supplementary Materials.

Supplementary Materials: Additional Figures S1-38 and Tables S1-10 are available online at http://www.mdpi. com/1996-1944/12/14/2314/s1.

Author Contributions: Conceptualization, methodology and formal analysis, D.F.E. and V.E.W.; investigation-single crystal XRD and cyclic voltammetry, D.M.; investigation-TD-DFT calculations, K.H.; investigation—all remaining experiments, D.F.E.; writing—original draft preparation, D.F.E.; writing — review and editing, D.F.E., V.E.W., and D.M.; supervision, project administration and funding acquisition, V.E.W.

Funding: We gratefully acknowledge the Natural Sciences and Engineering Research Council of Canada (NSERC) and Simon Fraser University (SFU) for funding. This work made use of the 4D Labs shared facilities supported by the Canada Foundation for Innovation (CFI), British Columbia Knowledge Development Fund (BCKDF), Western Economic Diversification (WD), and SFU. The computational work was enabled in part by support provided by Compute Canada and the Graham server.

Acknowledgments: We would like to thank Wen Zhou for performing thermogravimetric analysis. We would like to express our great appreciation to Loren Kaake (SFU) for input on the opto-electronic properties.

Conflicts of Interest: The authors declare no conflicts of interest.

\section{References}

1. Lee, E.K.; Lee, M.Y.; Park, C.H.; Lee, H.R.; Oh, J.H. Toward Environmentally Robust Organic Electronics: Approaches and Applications. Adv. Mater. 2017, 29, 1703638. [CrossRef]

2. Someya, T.; Bao, Z.; Malliaras, G.G. The rise of plastic bioelectronics. Nature 2016, 540, 379-385. [CrossRef] [PubMed]

3. Dou, L.; Liu, Y.; Hong, Z.; Li, G.; Yang, Y. Low-Bandgap Near-IR Conjugated Polymers/Molecules for Organic Electronics. Chem. Rev. 2015, 115, 12633-12665. [CrossRef] [PubMed]

4. Orgiu, E.; Samorì, P. 25th Anniversary Article: Organic Electronics Marries Photochromism: Generation of Multifunctional Interfaces, Materials, and Devices. Adv. Mater. 2014, 26, 1827-1845. [CrossRef] [PubMed]

5. Song, J.; Kim, K.-H.; Kim, E.; Moon, C.-K.; Kim, Y.-H.; Kim, J.-J.; Yoo, S. Lensfree OLEDs with over 50\% external quantum efficiency via external scattering and horizontally oriented emitters. Nat. Commun. 2018, 9, 3207. [CrossRef] [PubMed]

6. Li, X.; Zhang, J.; Zhao, Z.; Wang, L.; Yang, H.; Chang, Q.; Jiang, N.; Liu, Z.; Bian, Z.; Liu, W.; et al. Deep Blue Phosphorescent Organic Light-Emitting Diodes with CIEy Value of 0.11 and External Quantum Efficiency up to $22.5 \%$. Adv. Mater. 2018, 30, 1705005. [CrossRef] [PubMed]

7. Cui, L.-S.; Ruan, S.-B.; Bencheikh, F.; Nagata, R.; Zhang, L.; Inada, K.; Nakanotani, H.; Liao, L.-S.; Adachi, C. Long-lived efficient delayed fluorescence organic light-emitting diodes using n-type hosts. Nat. Commun. 2017, 8, 2250. [CrossRef] [PubMed]

8. Wong, M.Y.; Zysman-Colman, E. Purely Organic Thermally Activated Delayed Fluorescence Materials for Organic Light-Emitting Diodes. Adv. Mater. 2017, 29, 1605444. [CrossRef]

9. Ji, D.; Li, T.; Zou, Y.; Chu, M.; Zhou, K.; Liu, J.; Tian, G.; Zhang, Z.; Zhang, X.; Li, L.; et al. Copolymer dielectrics with balanced chain-packing density and surface polarity for high-performance flexible organic electronics. Nat. Commun. 2018, 9, 2339. [CrossRef]

10. Baumgarten, M.; Hu, B.-L.; Zhang, K.; An, C.; Schollmeyer, D.; Pisula, W. Layered Thiadiazoloquinoxaline Containing Long Pyrene-fused N-Heteroacenes. Angew. Chem. Int. Ed. 2018, 57, 12375-12379.

11. Hu, D.; Wang, X.; Chen, H.; Guo, T. High Performance Flexible Nonvolatile Memory Based on Vertical Organic Thin Film Transistor. Adv. Funct. Mater. 2017, 27, 1703541. [CrossRef]

12. Kanagasekaran, T.; Shimotani, H.; Shimizu, R.; Hitosugi, T.; Tanigaki, K. A new electrode design for ambipolar injection in organic semiconductors. Nat. Commun. 2017, 8, 999. [CrossRef] 
13. Hailey, A.K.; Petty, A.J.; Washbourne, J.; Thorley, K.J.; Parkin, S.R.; Anthony, J.E.; Loo, Y.-L. Understanding the Crystal Packing and Organic Thin-Film Transistor Performance in Isomeric Guest-Host Systems. Adv. Mater. 2017, 29, 1700048. [CrossRef]

14. Liu, W.; Zhang, J.; Zhou, Z.; Zhang, D.; Zhang, Y.; Xu, S.; Zhu, X. Design of a New Fused-Ring Electron Acceptor with Excellent Compatibility to Wide-Bandgap Polymer Donors for High-Performance Organic Photovoltaics. Adv. Mater. 2018, 30, 1800403. [CrossRef]

15. Nam, M.; Cha, M.; Lee, H.H.; Hur, K.; Lee, K.-T.; Yoo, J.; Han, I.K.; Kwon, S.J.; Ko, D.-H. Long-term efficient organic photovoltaics based on quaternary bulk heterojunctions. Nat. Commun. 2017, 8, 14068. [CrossRef]

16. Baran, D.; Ashraf, R.S.; Hanifi, D.A.; Abdelsamie, M.; Gasparini, N.; Röhr, J.A.; Holliday, S.; Wadsworth, A.; Lockett, S.; Neophytou, M.; et al. Reducing the efficiency-stability-cost gap of organic photovoltaics with highly efficient and stable small molecule acceptor ternary solar cells. Nat. Mater. 2017, 16, 363-369. [CrossRef]

17. Nian, L.; Gao, K.; Jiang, Y.; Rong, Q.; Hu, X.; Yuan, D.; Liu, F.; Peng, X.; Russell, T.P.; Zhou, G. Small-Molecule Solar Cells with Simultaneously Enhanced Short-Circuit Current and Fill Factor to Achieve 11\% Efficiency. Adv. Mater. 2017, 29, 1700616. [CrossRef]

18. Sutton, C.; Risko, C.; Brédas, J.-L. Noncovalent Intermolecular Interactions in Organic Electronic Materials: Implications for the Molecular Packing vs. Electronic Properties of Acenes. Chem. Mater. 2016, 28, 3-16. [CrossRef]

19. Pfattner, R.; Bromley, S.T.; Rovira, C.; Mas-Torrent, M. Tuning Crystal Ordering, Electronic Structure, and Morphology in Organic Semiconductors: Tetrathiafulvalenes as a Model Case. Adv. Funct. Mater. 2016, 26, 2256-2275. [CrossRef]

20. Ryno, S.M.; Risko, C.; Brédas, J.-L. Impact of Molecular Packing on Electronic Polarization in Organic Crystals: The Case of Pentacene vs TIPS-Pentacene. J. Am. Chem. Soc. 2014, 136, 6421-6427. [CrossRef]

21. Rivnay, J.; Jimison, L.H.; Northrup, J.E.; Toney, M.F.; Noriega, R.; Lu, S.; Marks, T.J.; Facchetti, A.; Salleo, A. Large modulation of carrier transport by grain-boundary molecular packing and microstructure in organic thin films. Nat. Mater. 2009, 8, 952-958. [CrossRef]

22. McDowell, C.; Abdelsamie, M.; Toney, M.F.; Bazan, G.C. Solvent Additives: Key Morphology-Directing Agents for Solution-Processed Organic Solar Cells. Adv. Mater. 2018, 30, 1707114. [CrossRef]

23. Zhang, X.; Jie, J.; Deng, W.; Shang, Q.; Wang, J.; Wang, H.; Chen, X.; Zhang, X. Alignment and Patterning of Ordered Small-Molecule Organic Semiconductor Micro-/Nanocrystals for Device Applications. Adv. Mater. 2016, 28, 2475-2503. [CrossRef]

24. Li, Z.; Xu, X.; Zhang, W.; Meng, X.; Ma, W.; Yartsev, A.; Inganäs, O.; Andersson, M.R.; Janssen, R.A.J.; Wang, E. High Performance All-Polymer Solar Cells by Synergistic Effects of Fine-Tuned Crystallinity and Solvent Annealing. J. Am. Chem. Soc. 2016, 138, 10935-10944. [CrossRef]

25. Deng, D.; Zhang, Y.; Zhang, J.; Wang, Z.; Zhu, L.; Fang, J.; Xia, B.; Wang, Z.; Lu, K.; Ma, W.; et al. Fluorination-enabled optimal morphology leads to over $11 \%$ efficiency for inverted small-molecule organic solar cells. Nat. Commun. 2016, 7, 13740. [CrossRef]

26. Yang, J.; Yan, D.; Jones, T.S. Molecular Template Growth and Its Applications in Organic Electronics and Optoelectronics. Chem. Rev. 2015, 115, 5570-5603. [CrossRef]

27. Niazi, M.R.; Li, R.; Li, E.Q.; Kirmani, A.R.; Abdelsamie, M.; Wang, Q.; Pan, W.; Payne, M.M.; Anthony, J.E.; Smilgies, D.-M.; et al. Solution-printed organic semiconductor blends exhibiting transport properties on par with single crystals. Nat. Commun. 2015, 6, 8598. [CrossRef]

28. Lee, C.; Kang, H.; Lee, W.; Kim, T.; Kim, K.-H.; Woo, H.Y.; Wang, C.; Kim, B.J. High-Performance All-Polymer Solar Cells Via Side-Chain Engineering of the Polymer Acceptor: The Importance of the Polymer Packing Structure and the Nanoscale Blend Morphology. Adv. Mater. 2015, 27, 2466-2471. [CrossRef]

29. Choi, D.; Chang, M.; Reichmanis, E. Controlled Assembly of Poly(3-hexylthiophene): Managing the Disorder to Order Transition on the Nano- through Meso-Scales. Adv. Funct. Mater. 2015, 25, 920-927. [CrossRef]

30. Wei, Q.; Mukaida, M.; Naitoh, Y.; Ishida, T. Morphological Change and Mobility Enhancement in PEDOT:PSS by Adding Co-solvents. Adv. Mater. 2013, 25, 2831-2836. [CrossRef]

31. Keum, C.M.; Liu, S.; Al-Shadeedi, A.; Kaphle, V.; Callens, M.K.; Han, L.; Neyts, K.; Zhao, H.; Gather, M.C.; Bunge, S.D.; et al. Tuning charge carrier transport and optical birefringence in liquid-crystalline thin films: A new design space for organic light-emitting diodes. Sci. Rep. 2018, 8, 699. [CrossRef] 
32. Nickmans, K.; Schenning, A.P.H.J. Directed Self-Assembly of Liquid-Crystalline Molecular Building Blocks for Sub-5 nm Nanopatterning. Adv. Mater. 2018, 30, 1703713. [CrossRef]

33. Uchida, J.; Yoshio, M.; Sato, S.; Yokoyama, H.; Fujita, M.; Kato, T. Self-Assembly of Giant Spherical Liquid-Crystalline Complexes and Formation of Nanostructured Dynamic Gels that Exhibit Self-Healing Properties. Angew. Chem. Int. Ed. 2017, 56, 14085-14089. [CrossRef]

34. Kaafarani, B.R. Discotic Liquid Crystals for Opto-Electronic Applications. Chem. Mater. 2011, 23, $378-396$. [CrossRef]

35. Feng, X.; Liu, M.; Pisula, W.; Takase, M.; Li, J.; Müllen, K. Supramolecular Organization and Photovoltaics of Triangle-shaped Discotic Graphenes with Swallow-tailed Alkyl Substituents. Adv. Mater. 2008, 20, 2684-2689. [CrossRef]

36. McCulloch, I.; Heeney, M.; Bailey, C.; Genevicius, K.; MacDonald, I.; Shkunov, M.; Sparrowe, D.; Tierney, S.; Wagner, R.; Zhang, W.; et al. Liquid-crystalline semiconducting polymers with high charge-carrier mobility. Nat. Mater. 2006, 5, 328-333. [CrossRef]

37. van Breemen, A.J.J.M.; Herwig, P.T.; Chlon, C.H.T.; Sweelssen, J.; Schoo, H.F.M.; Setayesh, S.; Hardeman, W.M.; Martin, C.A.; de Leeuw, D.M.; Valeton, J.J.P.; et al. Large Area Liquid Crystal Monodomain Field-Effect Transistors. J. Am. Chem. Soc. 2006, 128, 2336-2345. [CrossRef]

38. Iguarbe, V.; Concellón, A.; Termine, R.; Golemme, A.; Barberá, J.; Serrano, J.L. Making Coaxial Wires Out of Janus Dendrimers for Efficient Charge Transport. ACS Macro Lett. 2018, 7, 1138-1143. [CrossRef]

39. Chico, R.; de Domingo, E.; Domínguez, C.; Donnio, B.; Heinrich, B.; Termine, R.; Golemme, A.; Coco, S.; Espinet, P. High One-Dimensional Charge Mobility in Semiconducting Columnar Mesophases of Isocyano-Triphenylene Metal Complexes. Chem. Mater. 2017, 29, 7587-7595. [CrossRef]

40. Wöhrle, T.; Wurzbach, I.; Kirres, J.; Kostidou, A.; Kapernaum, N.; Litterscheidt, J.; Haenle, J.C.; Staffeld, P.; Baro, A.; Giesselmann, F.; et al. Discotic Liquid Crystals. Chem. Rev. 2016, 116, 1139-1241. [CrossRef]

41. García-Frutos, E.M.; Pandey, U.K.; Termine, R.; Omenat, A.; Barberá, J.; Serrano, J.L.; Golemme, A.; Gómez-Lor, B. High Charge Mobility in Discotic Liquid-Crystalline Triindoles: Just a Core Business? Angew. Chem. Int. Ed. 2011, 50, 7399-7402. [CrossRef]

42. Thiebaut, O.; Bock, H.; Grelet, E. Face-on Oriented Bilayer of Two Discotic Columnar Liquid Crystals for Organic Donor-Acceptor Heterojunction. J. Am. Chem. Soc. 2010, 132, 6886-6887. [CrossRef]

43. Pisula, W.; Feng, X.; Müllen, K. Tuning the Columnar Organization of Discotic Polycyclic Aromatic Hydrocarbons. Adv. Mater. 2010, 22, 3634-3649. [CrossRef]

44. Feng, X.; Marcon, V.; Pisula, W.; Hansen, M.R.; Kirkpatrick, J.; Grozema, F.; Andrienko, D.; Kremer, K.; Müllen, K. Towards high charge-carrier mobilities by rational design of the shape and periphery of discotics. Nat. Mater. 2009, 8, 421-426. [CrossRef]

45. Kato, T.; Yoshio, M.; Ichikawa, T.; Soberats, B.; Ohno, H.; Funahashi, M. Transport of ions and electrons in nanostructured liquid crystals. Nat. Rev. Mater. 2017, 2, 17001. [CrossRef]

46. Iino, H.; Hanna, J. Liquid crystalline organic semiconductors for organic transistor applications. Polym. J. 2017, 49, 23-30. [CrossRef]

47. He, Y.; Sezen, M.; Zhang, D.; Li, A.; Yan, L.; Yu, H.; He, C.; Goto, O.; Loo, Y.-L.; Meng, H. High Performance OTFTs Fabricated Using a Calamitic Liquid Crystalline Material of 2-(4-Dodecyl phenyl)[1]benzothieno[3,2-b][1]benzothiophene. Adv. Electron. Mater. 2016, 2, 1600179. [CrossRef]

48. Iino, H.; Usui, T.; Hanna, J. Liquid crystals for organic thin-film transistors. Nat. Commun. 2015, 6, 6828. [CrossRef]

49. Roncali, J.; Leriche, P.; Cravino, A. From One- to Three-Dimensional Organic Semiconductors: In Search of the Organic Silicon? Adv. Mater. 2007, 19, 2045-2060. [CrossRef]

50. Boucher, N.; Leroy, J.; Sergeyev, S.; Pouzet, E.; Lemaur, V.; Lazzaroni, R.; Cornil, J.; Geerts, Y.H.; Sferrazza, M. Mesomorphism of dialkylterthiophene homologues. Synth. Met. 2009, 159, 1319-1324. [CrossRef]

51. Leroy, J.; Boucher, N.; Sergeyev, S.; Sferrazza, M.; Geerts, Y.H. Symmetrical and Nonsymmetrical Liquid Crystalline Oligothiophenes: Convenient Synthesis and Transition-Temperature Engineering. Eur. J. Org. Chem. 2007, 2007, 1256-1261. [CrossRef]

52. Leroy, J.; Levin, J.; Sergeyev, S.; Geerts, Y. Practical One-step Synthesis of Symmetrical Liquid Crystalline Dialkyloligothiophenes for Molecular Electronic Applications. Chem. Lett. 2006, 35, 166-167. [CrossRef]

53. Funahashi, M.; Hanna, J. High ambipolar carrier mobility in self-organizing terthiophene derivative. Appl. Phys. Lett. 2000, 76, 2574-2576. [CrossRef] 
54. Byron, D.J.; Matharu, A.S.; Wilson, R.C.; Wright, G. The Synthesis and Liquid Crystal Properties of Certain 5,5"-Disubstituted 2,2':5',2"-Terthienyls. Mol. Cryst. Liq. Cryst. Sci. Technol. Sect. A Mol. Cryst. Liq. Cryst. 1995, 264, 227-230. [CrossRef]

55. Byron, D.; Matharu, A.; Wilson, R.; Wright, G. The Synthesis and Liquid Crystal Properties of Certain 5,5"-Disubstituted 2,2':5',2"-Terthiophenes. Mol. Cryst. Liq. Cryst. Sci. Technol. Sect. A Mol. Cryst. Liq. Cryst. 1995, 265, 61-76. [CrossRef]

56. Hanna, J.; Ohno, A.; Iino, H. Charge carrier transport in liquid crystals. Thin Solid Films 2014, 554, 58-63. [CrossRef]

57. Funahashi, M.; Yasuda, T.; Kato, T. Liquid Crystal Semiconductors: Oligothiophene and Related Materials. In Handbook of Liquid Crystals; Goodby, J.W., Collings, P.J., Kato, T., Tschierske, C., Gleeson, H., Raynes, E.P., Eds.; Wiley-VCH Verlag GmbH \& Co. KGaA: Weinheim, Germany, 2014; Volume 8, pp. 675-708. ISBN 978-3-527-67140-3.

58. Pisula, W.; Zorn, M.; Chang, J.Y.; Müllen, K.; Zentel, R. Liquid Crystalline Ordering and Charge Transport in Semiconducting Materials. Macromol. Rapid Commun. 2009, 30, 1179-1202. [CrossRef]

59. Iino, H.; Hanna, J. Availability of Liquid Crystallinity in Solution Processing for Polycrystalline Thin Films. Adv. Mater. 2011, 23, 1748-1751. [CrossRef]

60. Iino, H.; Hanna, J.-I. Liquid Crystalline Materials for Organic Polycrystalline Field Effect Transistors. Mol. Cryst. Liq. Cryst. 2011, 542, 237-243. [CrossRef]

61. Mei, J.; Diao, Y.; Appleton, A.L.; Fang, L.; Bao, Z. Integrated Materials Design of Organic Semiconductors for Field-Effect Transistors. J. Am. Chem. Soc. 2013, 135, 6724-6746. [CrossRef]

62. Funahashi, M.; Hanna, J.-I. High Carrier Mobility up to $0.1 \mathrm{~cm}^{2} \mathrm{~V}^{-1} \mathrm{~s}^{-1}$ at Ambient Temperatures in Thiophene-Based Smectic Liquid Crystals. Adv. Mater. 2005, 17, 594-598. [CrossRef]

63. Funahashi, M. Electronic Carrier Transport in Liquid Crystalline Semiconductors-Increase in Carrier Mobility and Extension of Mesomorphic Temperature Range. Mol. Cryst. Liq. Cryst. 2006, 458, 3-10. [CrossRef]

64. Funahashi, M.; Zhang, F.; Tamaoki, N.; Hanna, J. Ambipolar Transport in the Smectic E Phase of 2-Propyl-5"'-Hexynylterthiophene Derivative over a Wide Temperature Range. ChemPhysChem 2008, 9, 1465-1473. [CrossRef]

65. Funahashi, M.; Hanna, J.-I. Mesomorphic behaviors and charge carrier transport in terthiophene derivatives. Mol. Cryst. Liq. Cryst. 2004, 410, 1-12. [CrossRef]

66. Zhang, F.; Funahashi, M.; Tamaoki, N. High-performance thin film transistors from semiconducting liquid crystalline phases by solution processes. Appl. Phys. Lett. 2007, 91, 63515. [CrossRef]

67. Ghosh, T.; Lehmann, M. Recent advances in heterocycle-based metal-free calamitics. J. Mater. Chem. C 2017, 5, 12308-12337. [CrossRef]

68. Tuzimoto, P.; Santos, D.M.P.O.; Moreira, T.D.S.; Cristiano, R.; Bechtold, I.H.; Gallardo, H. Luminescent liquid crystals containing a sulphur-based heterocyclic core. Liq. Cryst. 2014, 41, 1097-1108. [CrossRef]

69. Han, J. 1,3,4-Oxadiazole based liquid crystals. J. Mater. Chem. C 2013, 1, 7779-7797. [CrossRef]

70. Kaur, S.; Tian, L.; Liu, H.; Greco, C.; Ferrarini, A.; Seltmann, J.; Lehmann, M.; Gleeson, H.F. The elastic and optical properties of a bent-core thiadiazole nematic liquid crystal: The role of the bend angle. J. Mater. Chem. C 2013, 1, 2416-2425. [CrossRef]

71. Seed, A. Synthesis of self-organizing mesogenic materials containing a sulfur-based five-membered heterocyclic core. Chem. Soc. Rev. 2007, 36, 2046-2069. [CrossRef]

72. Oikawa, K.; Tsuchiya, K.; Yamazaki, H. Fluorescent and Liquid Crystalline Thiophenes, and Their Compositions and Polymers. Patent JP 2004269424, 30 September 2004.

73. Kuo, C.Y.; Liu, Y.; Yarotski, D.; Li, H.; Xu, P.; Yen, H.J.; Tretiak, S.; Wang, H.L. Synthesis, electrochemistry, STM investigation of oligothiophene self-assemblies with superior structural order and electronic properties. Chem. Phys. 2016, 481, 191-197. [CrossRef]

74. Pu, S.; Zhu, S.; Rao, Y.; Liu, G.; Wei, H. Photochromism of 1,2-bis(2-n-alkyl-5-formyl-3-thienyl)perfluorocyclopentene derivatives. J. Mol. Struct. 2009, 921, 89-100. [CrossRef]

75. Screttas, C.G.; Steele, B.R. Metal alkoxide modified organometallic reagents. Preparation and stability of organolithium reagents in tetrahydrofuran in the presence of magnesium 2-ethoxyethoxide. J. Org. Chem. 1989, 54, 1013-1017. [CrossRef] 
76. Chen, H.; Liu, Z.; Zhao, Z.; Zheng, L.; Tan, S.; Yin, Z.; Zhu, C.; Liu, Y. Synthesis, Structural Characterization, and Field-Effect Transistor Properties of n-Channel Semiconducting Polymers Containing Five-Membered Heterocyclic Acceptors: Superiority of Thiadiazole Compared with Oxadiazole. ACS Appl. Mater. Interfaces 2016, 8, 33051-33059. [CrossRef]

77. Kurach, E.; Kotwica, K.; Zapala, J.; Knor, M.; Nowakowski, R.; Djurado, D.; Toman, P.; Pfleger, J.; Zagorska, M.; Pron, A. Semiconducting Alkyl Derivatives of 2,5-Bis(2,2'-bithiophene-5-yl)-1,3,4-thiadiazole-Effect of the Substituent Position on the Spectroscopic, Electrochemical, and Structural Properties. J. Phys. Chem. C 2013, 117, 15316-15326. [CrossRef]

78. Gane, P.A.C.; Leadbetter, A.J.; Moussa, F.; Benattar, J.J.; Lambert, M. Structural correlations in smectic-F and smectic-I phases. Phys. Rev. A 1981, 24, 2694-2700. [CrossRef]

79. Getmanenko, Y.A.; Kang, S.-W.; Shakya, N.; Pokhrel, C.; Bunge, S.D.; Kumar, S.; Ellman, B.D.; Twieg, R.J. Bis(5-alkylthiophen-2-yl)arene liquid crystals as molecular semiconductors. J. Mater. Chem. C 2014, 2, 2600-2611. [CrossRef]

80. Getmanenko, Y.A.; Kang, S.-W.; Shakya, N.; Pokhrel, C.; Bunge, S.D.; Kumar, S.; Ellman, B.D.; Twieg, R.J. 5,5'-Bis-(alkylpyridinyl)-2,2'-bithiophenes: Synthesis, liquid crystalline behaviour and charge transport. J. Mater. Chem. C 2013, 2, 256-271. [CrossRef]

81. Kim, S.; Kim, A.; Jang, K.-S.; Yoo, S.; Ka, J.-W.; Kim, J.; Yi, M.H.; Won, J.C.; Hong, S.-K.; Kim, Y.H. The effect of thermal annealing on the layered structure of smectic liquid crystalline organic semiconductor on polyimide gate insulator and its OFET performance. Synth. Met. 2016, 220, 311-317. [CrossRef]

82. Ward, J.W.; Goetz, K.P.; Obaid, A.; Payne, M.M.; Diemer, P.J.; Day, C.S.; Anthony, J.E.; Jurchescu, O.D. Low-temperature phase transitions in a soluble oligoacene and their effect on device performance and stability. Appl. Phys. Lett. 2014, 105, 83305. [CrossRef]

83. Jurchescu, O.D.; Mourey, D.A.; Subramanian, S.; Parkin, S.R.; Vogel, B.M.; Anthony, J.E.; Jackson, T.N.; Gundlach, D.J. Effects of polymorphism on charge transport in organic semiconductors. Phys. Rev. B 2009, 80, 85201. [CrossRef]

84. Kato, T.; Uchida, J.; Ichikawa, T.; Sakamoto, T. Functional Liquid Crystals towards the Next Generation of Materials. Angew. Chem. Int. Ed. 2018, 57, 4355-4371. [CrossRef]

85. Goodby, J.W. Structures and Properties of Smectic Liquid Crystals. In Handbook of Liquid Crystals; Goodby, J.W., Collings, P.J., Kato, T., Tschierske, C., Gleeson, H., Raynes, P., Eds.; Wiley-VCH Verlag GmbH \& Co. KGaA: Weinheim, Germany, 2014; Volume 4, pp. 43-68, ISBN 978-3-527-67140-3.

86. Horčic, M.; Kozmík, V.; Svoboda, J.; Novotná, V.; Pociecha, D. Transformation from a rod-like to a hockey-stick-like and bent-shaped molecule in 3,4'-disubstituted azobenzene-based mesogens. J. Mater. Chem. C 2013, 1, 7560-7567. [CrossRef]

87. Kajitani, T.; Kohmoto, S.; Yamamoto, M.; Kishikawa, K. Liquid crystalline amides: Linear arrangement of rod-like molecules by lateral intermolecular hydrogen bonding and molecular shape effect. J. Mater. Chem. 2004, 14, 3449-3456. [CrossRef]

88. Pradhan, B.; Vaisakh, V.M.; Nair, G.G.; Rao, D.S.S.; Prasad, S.K.; Sudhakar, A.A. Effect of Atomic-Scale Differences on the Self-Assembly of Thiophene-based Polycatenars in Liquid Crystalline and Organogel States. Chem.-Eur. J. 2016, 22, 17843-17856. [CrossRef]

89. Han, J.; Zhang, F.-Y.; Wang, J.-Y.; Wang, Y.-M.; Pang, M.-L.; Meng, J.-B. Synthesis and comparative study of the heterocyclic rings on liquid crystalline properties of 2,5-aryl-1,3,4-oxa(thia)diazole derivatives containing furan and thiophene units. Liq. Cryst. 2009, 36, 825-833. [CrossRef]

90. Han, J.; Chang, X.-Y.; Cao, B.-N.; Wang, Q.-C. Synthesis, Single Crystal Structures, and Liquid Crystal Property of 2,5-Diphenyl-1,3,4-Oxadiazoles/1,3,4-Thiadiazoles. Soft Mater. 2009, 7, 342-354. [CrossRef]

91. Han, J.; Wang, J.-Y.; Zhang, F.-Y.; Zhu, L.-R.; Pang, M.-L.; Meng, J.-B. Synthesis and mesomorphic behaviour of heterocycle-based liquid crystals containing 1,3,4-oxadiazole/thiadiazole and thiophene units. Liq. Cryst. 2008, 35, 1205-1214. [CrossRef]

92. Lavigueur, C.; Foster, E.J.; Williams, V.E. Self-Assembly of Discotic Mesogens in Solution and in Liquid Crystalline Phases: Effects of Substituent Position and Hydrogen Bonding. J. Am. Chem. Soc. 2008, 130, 11791-11800. [CrossRef]

93. Foster, E.J.; Jones, R.B.; Lavigueur, C.; Williams, V.E. Structural Factors Controlling the Self-Assembly of Columnar Liquid Crystals. J. Am. Chem. Soc. 2006, 128, 8569-8574. [CrossRef] 
94. Lercher, C.; Röthel, C.; Roscioni, O.M.; Geerts, Y.H.; Shen, Q.; Teichert, C.; Fischer, R.; Leising, G.; Sferrazza, M.; Gbabode, G.; et al. Polymorphism of dioctyl-terthiophene within thin films: The role of the first monolayer. Chem. Phys. Lett. 2015, 630, 12-17. [CrossRef]

95. Van Bolhuis, F.; Wynberg, H.; Havinga, E.E.; Meijer, E.W.; Staring, E.G.J. The X-ray structure and MNDO calculations of $\alpha$-terthienyl: A model for polythiophenes. Synth. Met. 1989, 30, 381-389. [CrossRef]

96. Dhar, J.; Karothu, D.P.; Patil, S. Herringbone to cofacial solid state packing via H-bonding in diketopyrrolopyrrole (DPP) based molecular crystals: Influence on charge transport. Chem. Commun. 2014, 51, 97-100. [CrossRef]

97. McGarry, K.A.; Xie, W.; Sutton, C.; Risko, C.; Wu, Y.; Young, V.G.; Brédas, J.-L.; Frisbie, C.D.; Douglas, C.J. Rubrene-Based Single-Crystal Organic Semiconductors: Synthesis, Electronic Structure, and Charge-Transport Properties. Chem. Mater. 2013, 25, 2254-2263. [CrossRef]

98. Wang, C.; Dong, H.; Hu, W.; Liu, Y.; Zhu, D. Semiconducting $\pi$-Conjugated Systems in Field-Effect Transistors: A Material Odyssey of Organic Electronics. Chem. Rev. 2012, 112, 2208-2267. [CrossRef]

99. Locklin, J.; Roberts, M.E.; Mannsfeld, S.C.B.; Bao, Z. Optimizing the Thin Film Morphology of Organic Field-Effect Transistors: The Influence of Molecular Structure and Vacuum Deposition Parameters on Device Performance. J. Macromol. Sci. Part C 2006, 46, 79-101. [CrossRef]

100. Hutchison, G.R.; Ratner, M.A.; Marks, T.J. Intermolecular Charge Transfer between Heterocyclic Oligomers. Effects of Heteroatom and Molecular Packing on Hopping Transport in Organic Semiconductors. J. Am. Chem. Soc. 2005, 127, 16866-16881. [CrossRef]

101. Oliva, M.M.; Pappenfus, T.M.; Melby, J.H.; Schwaderer, K.M.; Johnson, J.C.; McGee, K.A.; da Silva Filho, D.A.; Bredas, J.-L.; Casado, J.; López Navarrete, J.T. Comparison of Thiophene-Pyrrole Oligomers with Oligothiophenes: A Joint Experimental and Theoretical Investigation of Their Structural and Spectroscopic Properties. Chem.-A Eur. J. 2010, 16, 6866-6876. [CrossRef]

102. Facchetti, A.; Yoon, M.-H.; Stern, C.L.; Hutchison, G.R.; Ratner, M.A.; Marks, T.J. Building Blocks for N-Type Molecular and Polymeric Electronics. Perfluoroalkyl- versus Alkyl-Functionalized Oligothiophenes (nTs; n = 2-6). Systematic Synthesis, Spectroscopy, Electrochemistry, and Solid-State Organization. J. Am. Chem. Soc. 2004, 126, 13480-13501. [CrossRef]

103. Nepomnyashchii, A.B.; Ono, R.J.; Lyons, D.M.; Bielawski, C.W.; Sessler, J.L.; Bard, A.J. Electrochemistry and electrogenerated chemiluminescence of thiophene and fluorene oligomers. Benzoyl peroxide as a coreactant for oligomerization of thiophene dimers. Chem. Sci. 2012, 3, 2628-2638. [CrossRef]

104. Bredas, J.L. Mind the gap! Mater. Horiz. 2013, 1, 17-19. [CrossRef]

105. Seixas de Melo, J.; Elisei, F.; Becker, R.S. Photophysical studies of mixed furan, pyrrole, and thiophene-containing oligomers with three and five rings. J. Chem. Phys. 2002, 117, 4428-4435. [CrossRef]

106. Jursic, B.S. Suitability of furan, pyrrole and thiophene as dienes for Diels-Alder reactions viewed through their stability and reaction barriers for reactions with acetylene, ethylene and cyclopropene. An AM1 semiempirical and B3LYP hybrid density functional theory study. J. Mol. Struct. THEOCHEM 1998, 454, 105-116.

107. Pineda, R.F.; Troughton, J.; Planells, M.; Santos, I.S.-M.; Muhith, F.; Nichol, G.S.; Haque, S.; Watson, T.; Robertson, N. Effect of alkyl chain length on the properties of triphenylamine-based hole transport materials and their performance in perovskite solar cells. Phys. Chem. Chem. Phys. 2018, 20, 1252-1260. [CrossRef]

108. Granadino-Roldán, J.M.; Garzón, A.; García, G.; Moral, M.; Navarro, A.; Fernández-Liencres, M.P.; Peña-Ruiz, T.; Fernández-Gómez, M. Theoretical Study of the Effect of Alkyl and Alkoxy Lateral Chains on the Structural and Electronic Properties of $\pi$-Conjugated Polymers Consisting of Phenylethynyl-1,3,4-thiadiazole. J. Phys. Chem. C 2011, 115, 2865-2873. [CrossRef]

109. Lavigueur, C.; Foster, E.J.; Williams, V.E. A simple and inexpensive capillary furnace for variable-temperature X-ray diffraction. J. Appl. Crystallogr. 2008, 41, 214-216. [CrossRef]

110. Tomasi, J.; Mennucci, B.; Cancès, E. The IEF version of the PCM solvation method: An overview of a new method addressed to study molecular solutes at the QM ab initio level. J. Mol. Struct. THEOCHEM 1999, 464, 211-226. [CrossRef]

111. Barone, V.; Cossi, M.; Tomasi, J. Geometry optimization of molecular structures in solution by the polarizable continuum model. J. Comput. Chem. 1998, 19, 404-417. [CrossRef] 
112. Barone, V.; Cossi, M.; Tomasi, J. A new definition of cavities for the computation of solvation free energies by the polarizable continuum model. J. Chem. Phys. 1997, 107, 3210-3221. [CrossRef]

113. Stephens, P.J.; Devlin, F.J.; Chabalowski, C.F.; Frisch, M.J. Ab Initio Calculation of Vibrational Absorption and Circular Dichroism Spectra Using Density Functional Force Fields. J. Phys. Chem. 1994, 98, 11623-11627. [CrossRef]

114. Becke, A.D. Density-functional thermochemistry. III. The role of exact exchange. J. Chem. Phys. 1993, 98, 5648-5652. [CrossRef]

115. Miertuš, S.; Scrocco, E.; Tomasi, J. Electrostatic interaction of a solute with a continuum. A direct utilizaion of AB initio molecular potentials for the prevision of solvent effects. Chem. Phys. 1981, 55, 117-129. [CrossRef]

116. Frisch, M.J.; Trucks, G.W.; Schlegel, H.B.; Scuseria, G.E.; Robb, M.A.; Cheeseman, J.R.; Scalmani, G.; Barone, V.; Petersson, G.A.; Nakatsuji, H. Gaussian 16, Revision B.01; Gaussian, Inc.: Wallingford, CT, USA, 2016.

117. Stratmann, R.E.; Scuseria, G.E.; Frisch, M.J. An efficient implementation of time-dependent density-functional theory for the calculation of excitation energies of large molecules. J. Chem. Phys. 1998, 109, 8218-8224. [CrossRef]

118. Casida, M.E. Time-Dependent Density Functional Response Theory for Molecules. In Recent Advances in Density Functional Methods; Recent Advances in Computational Chemistry; World Scientific: Singapore, 1995; Volume 1, pp. 155-192. ISBN 978-981-02-2442-4.

119. Huff, G.S.; Gallaher, J.K.; Hodgkiss, J.M.; Gordon, K.C. No single DFT method can predict Raman cross-sections, frequencies and electronic absorption maxima of oligothiophenes. Synth. Met. 2017, 231, 1-6. [CrossRef]

120. Jacquemin, D.; Michaux, C.; Perpète, E.A.; Maurel, F.; Perrier, A. Photochromic molecular wires: Insights from theory. Chem. Phys. Lett. 2010, 488, 193-197. [CrossRef]

121. Yanai, T.; Tew, D.P.; Handy, N.C. A new hybrid exchange-correlation functional using the Coulomb-attenuating method (CAM-B3LYP). Chem. Phys. Lett. 2004, 393, 51-57. [CrossRef]

122. Schäfer, A.; Huber, C.; Ahlrichs, R. Fully optimized contracted Gaussian basis sets of triple zeta valence quality for atoms Li to Kr. J. Chem. Phys. 1994, 100, 5829-5835. [CrossRef]

123. Schäfer, A.; Horn, H.; Ahlrichs, R. Fully optimized contracted Gaussian basis sets for atoms Li to Kr. J. Chem. Phys. 1992, 97, 2571-2577. [CrossRef]

(C) 2019 by the authors. Licensee MDPI, Basel, Switzerland. This article is an open access article distributed under the terms and conditions of the Creative Commons Attribution (CC BY) license (http://creativecommons.org/licenses/by/4.0/). 